\title{
Analysis of the moisture effect on the mechanical behaviour of an adhesively bonded joint under proportional multi-axial loads
}

\author{
Arnaud N. ${ }^{1}$, Creac'hcadec R. ${ }^{1,}{ }^{\star}$, Cognard J. Y. ${ }^{1}$, Davies Peter ${ }^{2}$, Le Gac Pierre-Yves ${ }^{2}$ \\ ${ }^{1}$ Univ Brest, Lab Brestois Mecan \& Syst, ENSTA Bretagne, EA4325,ENIB,UEB, F-29806 Brest, France. \\ 2 IFREMER, Mat \& Struct Grp, Ctr Brest, F-29280 Plouzane, France. \\ * Corresponding author: Romain Creac'hcadec, \\ email address : Romain.Creachcadec@ensta-bretagne.fr
}

\begin{abstract}
:
The objective of the study is to identify the 3D behaviour of an adhesive in an assembly, and to take into account the effect of ageing in a marine environment. To that end, three different tests were employed. Gravimetric analyses were used to determine the water diffusion kinetics in the adhesive. Bulk tensile tests were performed to highlight the effects of humid ageing on the adhesive behaviour. Modified Arcan tests were performed for several ageing times to obtain the experimental database which was necessary to identify constitutive models. A Mahnken-Schlimmer type model was determined for the unaged state according to a procedure developed in a previous study. This identification used inverse techniques. It was based on the unaged modified Arcan results and on a coupling between an optimisation routine and finite-element analysis. Then, a global inverse identification procedure was developed. Its aim was to relate the unaged parameters to the moisture concentration and overcome the difficulties usually associated with ageing of bonded assemblies in a humid environment: a nonuniformity of the stress state and a gradient of mechanical properties in the adhesive. This procedure was similar to the one used in the first part but needed modified Arcan results for several ageing times. It also required an initial assumption for the evolution of the Mahnken-Schlimmer parameters with the moisture concentration.
\end{abstract}

Keywords : water resistance, Arcan test, ageing, epoxides, finite-element stress analysis, durability 


\section{Introduction}

Adhesive bonding is nowadays widespread since it offers many advantages over traditional assembly techniques [1-3]. However the issue of durability, especially in humid environments remains a limiting factor. Indeed these environments can be very severe and can cause changes in the adhesive. These changes can be reversible (plasticization, swelling) or permanent (hydrolysis, osmotic degradation...) [4-7]. The substrate/adhesive interface can also be affected (corrosion, cracking...) [8-9]. Many studies have been performed to analyse the influence of humid aging on the mechanical behaviour of adhesive joints and to model the assembly degradation. The classical approach illustrated by Crocombe et al. [10-13] is to determine the moisture diffusion laws for the adhesive and to identify constitutive model parameters dependent on the moisture concentration. Coupling these two sets of data in a numerical model allows the behaviour of a bonded structure to be predicted during humid aging.

The parameters which are followed are of two types: When a fracture mechanics approach is chosen, the identification of moisture dependant parameters can be carried out using either the Boeing wedge test $[4,14]$ or the TDCB specimen [15]. In the stress-based approach, Single or Double Lap Joint tests are mainly used [16-18]. However, the latter are associated with a complex tri-dimensional stress state and do not produce sufficient data to identify accurate constitutive models.

Indeed, the behaviour of structural adhesives is complex, even without aging. The dependency on the hydrostatic stress has been illustrated experimentally [19-23] and numerically [24-26] and must therefore be taken into account. Adhesive joints subjected to combined loads exhibit a large ratio between the tangential and normal non-linear response [27-28], thus making it necessary to use the non-associated formalism to describe their behaviour. Moreover, advanced models with several parameters must be employed to accurately predict the elastic-plastic behaviour of adhesives, such as the Mahnken-Schlimmer model. A large experimental database under various multi-axial loads is then required to identify these material parameters and validate the model $[25,26,28]$.

To that end, a modified Arcan device has been developed in a previous study [29]. Bordes et al. used this test in a first attempt to predict long term strength of adhesively bonded joints and highlighted its capacities by showing the evolution of yield stress envelopes with humid aging [18]. Maurice et al. have also successfully used the modified Arcan test to identify a Mahnken-Schlimmer type model for an unaged adhesive [26]. They also concluded that the Mahnken-Schlimmer model is well suited to describe the behaviour of aeronautical film adhesives, as Mahnken and Schlimmer [25] and Jousset et al. [28] demonstrated earlier for automotive adhesives.

The aim of the present study is to take advantage of the modified Arcan capacities -the availability of a large experimental database under various multi-axial loads - to identify the moisture effect on the mechanical behaviour of an adhesive in an assembly. First, the mechanical behaviour for an unaged state was determined, and the unaged material parameters of a Mahnken-Schlimmer model were identified. Then, a strategy was developed to include the effect of aging in the model, which requires making the mechanical parameters dependent on the moisture concentration.

\section{Mechanical characterisation of the unaged state}

Before analysing the effect of moisture ingress in an adhesive, it is necessary to identify the mechanical behaviour of the adhesive in its unaged state. 


\section{a. Experimental procedure}

The large database under multi-axial loads required to identify the parameters of a MahnkenSchlimmer model was obtained using a modified Arcan test. To determine these parameters, the identification method defined by Maurice et al. [26] was used. Moreover, some tensile tests were performed on bulk adhesive dog-bone specimens for subsequent comparison to aged samples.

The adhesive used in this study is a two-part epoxy adhesive Hysol EA9309.3NA (Structil, Vert-lepetit, France). The curing cycle was $24 \mathrm{~h}$ at room temperature followed by $22 \mathrm{~h}$ at $100^{\circ} \mathrm{C}$. Aluminium 2017 substrates were employed in the case of bonded samples. For these, a sulphuric acid anodisation of the substrates was applied as it is representative of aeronautical pre-treatments and as it allows a good protection of the bonding surface. The joint thickness was $0.4 \mathrm{~mm}$, which is representative of industrial structural bonding. The tests were displacement driven with a crosshead speed of $0.5 \mathrm{~mm} / \mathrm{min}$.

b. Bulk adhesive tensile tests

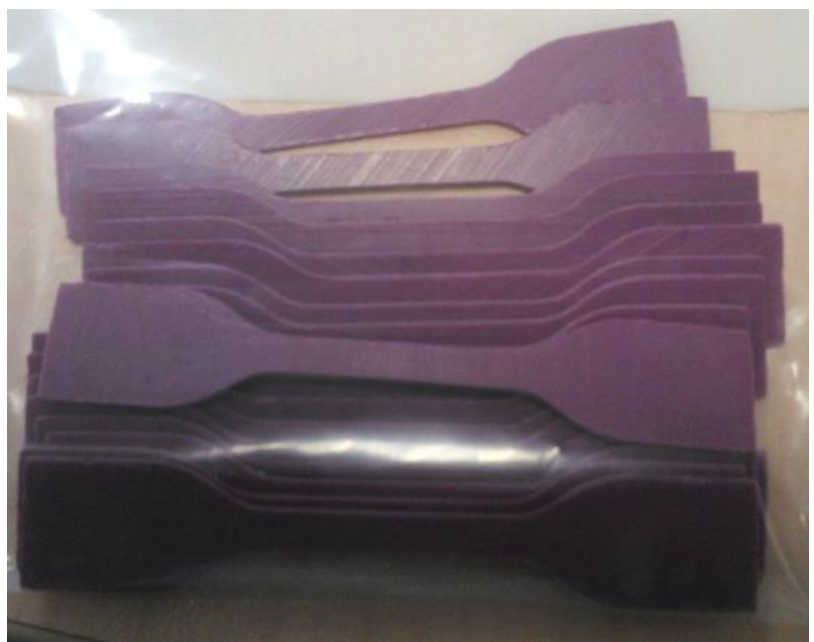

(a)

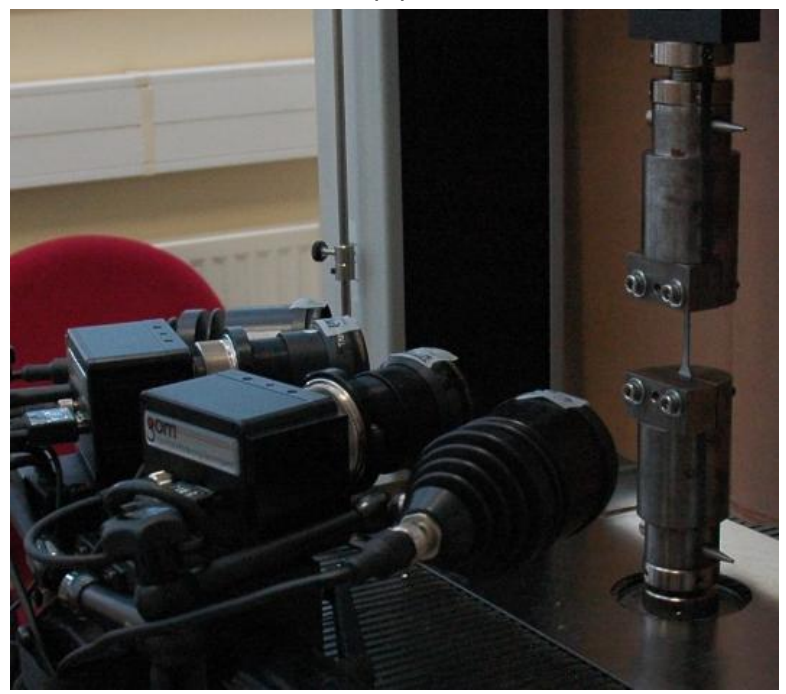

(c)

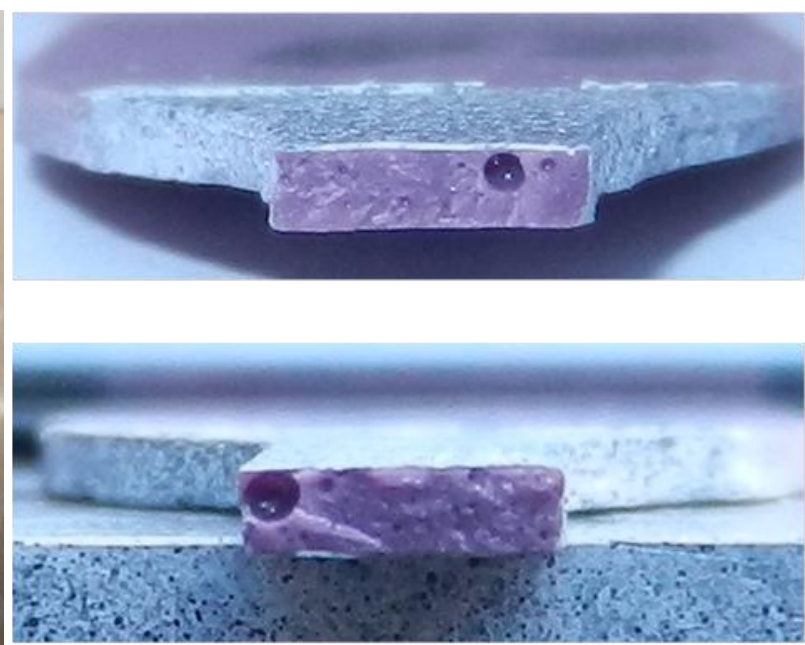

(b)

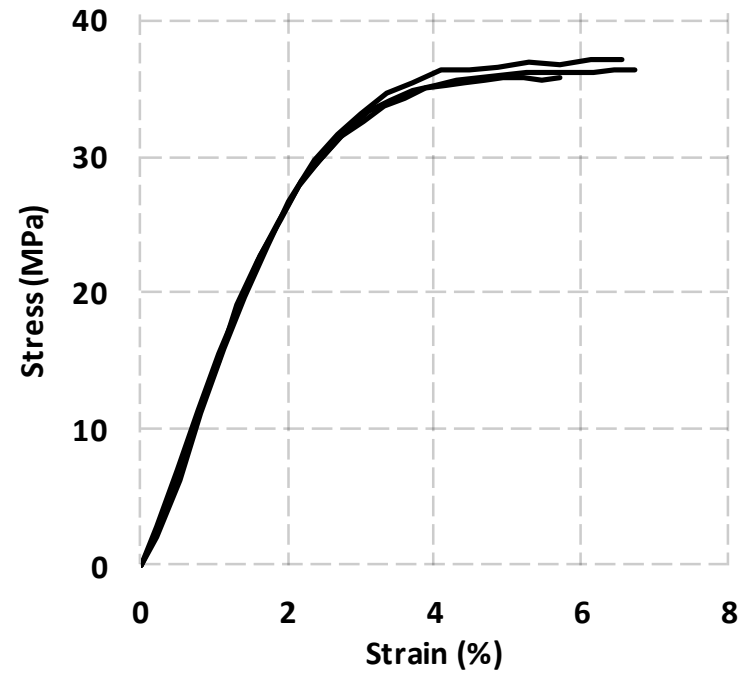

(d)

Fig. 1. Tensile tests on bulk samples: (a) Dog-bone samples, (b) Air bubbles in the section, (c) Test and Digital Image Correlation system and (d) Stress-Strain curves.

Bulk specimens were taken from a $1 \mathrm{~mm}$ thick adhesive film using a perforating punch according to the French standard [30]. The dog-bone samples had a cross section of $1 \mathrm{~mm} * 4 \mathrm{~mm}$ and a useful 
length of $30 \mathrm{~mm}$ (Fig. 1a). A $1 \mathrm{kN}$ tension machine (Lloyd Materials Testing) was employed. The tests were performed according to [31] with a crosshead speed of $37.5 \mathrm{~mm} / \mathrm{min}$. This resulted in strain rates of the same order of magnitude as the $0.4 \mathrm{~mm}$ thick bonded samples. Strains were measured with a 3D Digital Image Correlation system GOM/Aramis [32] (Fig.1c). Three samples were tested and the stress-strain curves are presented in Fig. 1d. This will be used later for a comparison with aged samples, as it represents the unaged state. Indeed a bulk tensile test is a rapid method to observe the effect of aging on the mechanical behaviour and thus on simple material parameters: Young's modulus and Poisson's ratio. These were determined from the curves to be: $\mathrm{E}=1.3 \mathrm{MPa}$ and $\mathrm{v}=$ 0.34. The plastic behaviour will not be considered here since it is very dependent on the defects present in the material such as air bubbles (Fig. 1b).

\section{c. Modified Arcan tests}

Cognard et al. developed a modified Arcan fixture in a previous study [29], based on three particularities:

- A unique bonded sample geometry designed to reduce edge effects. This involves beaks machined around the substrates close to the bonding surface (Fig. 2a).

- A special loading fixture that does not disturb the stress state in the adhesive, presented in Fig. 2c.

- A wide range of proportional loading paths available including tension, shear, mixed tensionshear and mixed compression-shear. These loadings respectively correspond in Fig. $2 \mathrm{~b}$ to $\gamma$ angles equals to $0^{\circ}, 90^{\circ}, 45^{\circ}$ and $135^{\circ}$.

In this study 3 samples were tested per loading direction, thus giving a 12 sample experimental campaign for the unaged assemblies. It can be divided into the tangential part (FT) and the normal part (FN) (Tab. 1) according to the $y$ angle (Fig. 2b).

\begin{tabular}{|c|c|c|}
\hline $\boldsymbol{\gamma}$ & $\mathbf{F N}$ & $\mathbf{F T}$ \\
\hline $\mathbf{0}^{\circ}$ & $\mathrm{F}$ & $\mathbf{0}$ \\
\hline $\mathbf{4 5 ^ { \circ }}$ & $\mathrm{F} / \sqrt{2}$ & $\mathrm{~F} / \sqrt{2}$ \\
\hline $\mathbf{9 0 ^ { \circ }}$ & $\mathbf{0}$ & $\mathrm{F}$ \\
\hline $\mathbf{1 3 5}^{\circ}$ & $-\mathrm{F} / \sqrt{2}$ & $\mathrm{~F} / \sqrt{2}$ \\
\hline
\end{tabular}

Tab. 1. Separation of the force (F) into tangential part (FT) and normal part (FN) according to the $\gamma$ angle.

Specimens were painted, as shown in Fig. 2a, in order to use a 3D Digital Image Correlation system, $\mathrm{GOM} /$ Aramis [GOM]. This allowed the displacements to be recorded on the sample surface. Fig. $2 \mathrm{~d}$ shows the zone recorded in the centre of the sample for a $45^{\circ}$ loading case (tension-shear), but the procedure to retrieve the displacements for other loadings is exactly the same. The two black lines were drawn prior to mounting the sample in the testing device. Their positions are accurately known and are the basis for a post-processing procedure. This procedure includes two steps: 


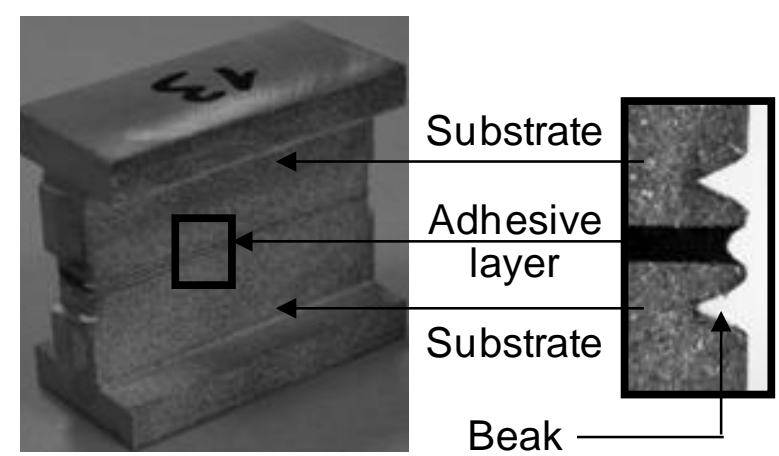

(a)

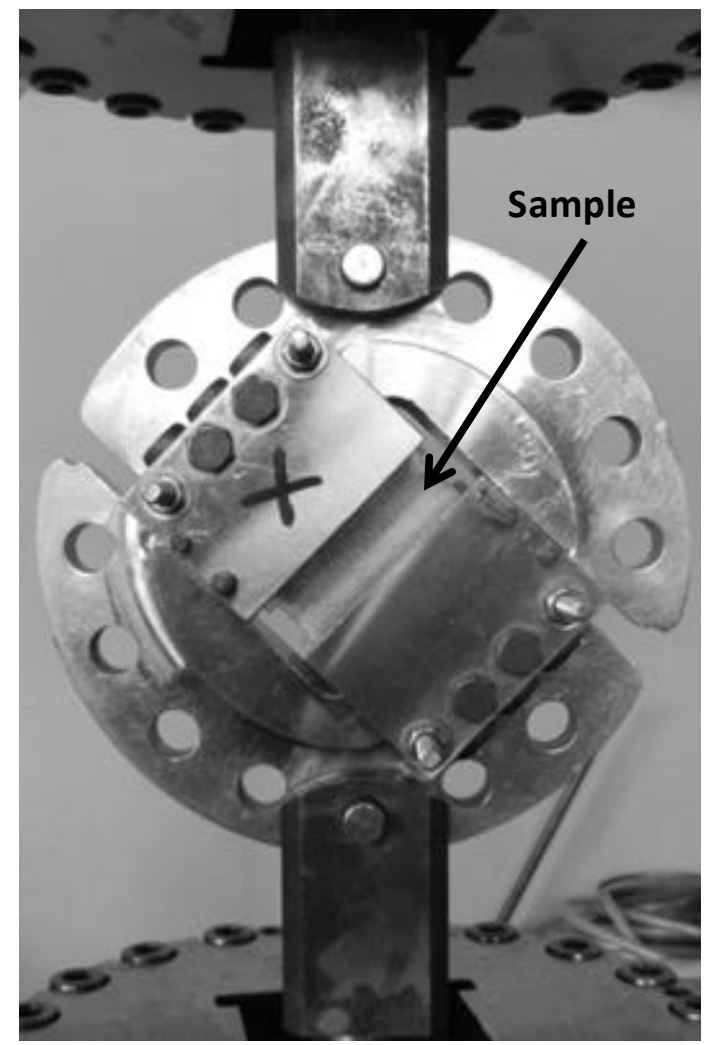

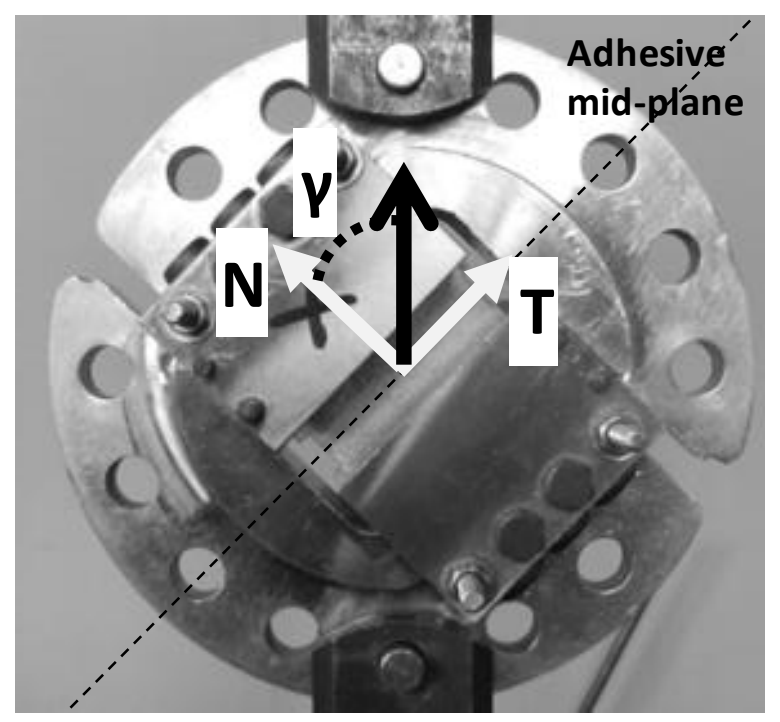

(b)

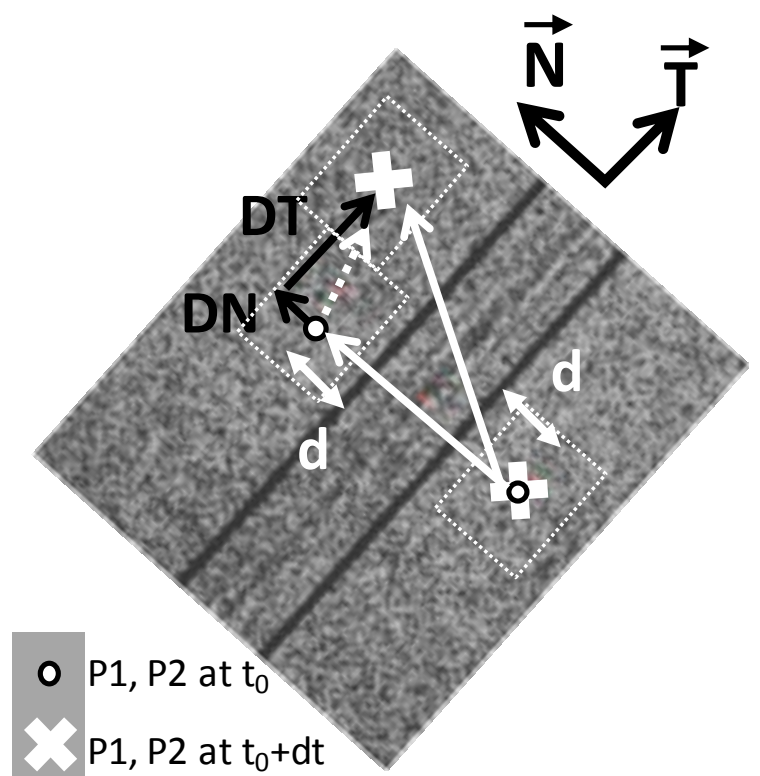

Fig. 2. Modified Arcan test: (a) Sample geometry with beaks, (b) Normal and tangential directions, (c) Testing device [29] and (d) Post-processing step to retrieve the normal and tangential displacements.

- The first step is the creation of a new frame of reference. It defines the normal and the tangential directions according to the $\gamma$ angle.

- The second step is the selection of a rectangular zone at a given distance (d) from the lower black line. All the displacements in this zone are then artificially set to 0 . The similar creation of a zone on the upper substrate centred on the upper point allows the displacements in that zone to be retrieved. The computation of a relative mean displacement is then possible. Initially this relative displacement is $\overrightarrow{D\left(t_{0}\right)}$ and it becomes $\overrightarrow{D\left(t_{0}+d t\right)}$ during the test. It can then be divided into a tangential part (DT) and a normal part (DN), according to (1). As the positions of the black lines and the distance $d$ are accurately known, it is possible to compute the displacement exactly at the same point for each Arcan test. This increases the repeatability of the test. It is also possible to accurately define in a finite-element model the point where the displacements are computed. 


$$
\begin{aligned}
& {\left[\overrightarrow{D\left(t_{0}+d t\right)}-\overrightarrow{D\left(t_{0}\right)}\right] \cdot \vec{N}=D N} \\
& {\left[\overrightarrow{D\left(t_{0}+d t\right)}-\overrightarrow{D\left(t_{0}\right)}\right] \cdot \vec{T}=D T}
\end{aligned}
$$

The modified Arcan test results are then tangential (or normal) force vs. relative tangential (or normal) displacement curves (FT-DT and FN-DN curves).

The samples were prepared according to the procedure presented earlier: aluminium anodised Arcan substrates bonded with EA9309.3NA. The modified Arcan device was loaded on a $100 \mathrm{kN}$ tensile test machine (Tema Concept, France). The results are presented in Fig. 3a for tension $\left(0^{\circ}\right)$, the normal part of tension-shear $\left(45^{\circ}\right)$ and the normal part of compression-shear $\left(135^{\circ}\right)$. In Fig. 3b are the results for shear $\left(90^{\circ}\right)$, the tangential part of tension-shear $\left(45^{\circ}\right)$ and the tangential part of compressionshear $\left(135^{\circ}\right)$. For ease of reading, compression-shear curves are plotted in absolute values on the same graphs as the other loading directions. The results show good repeatability, and are well suited for a constitutive model identification.

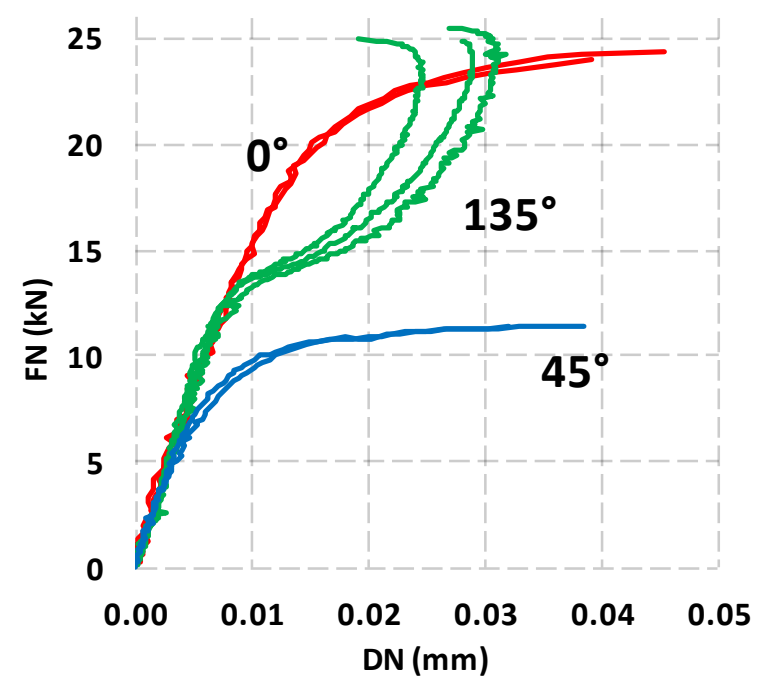

(a)

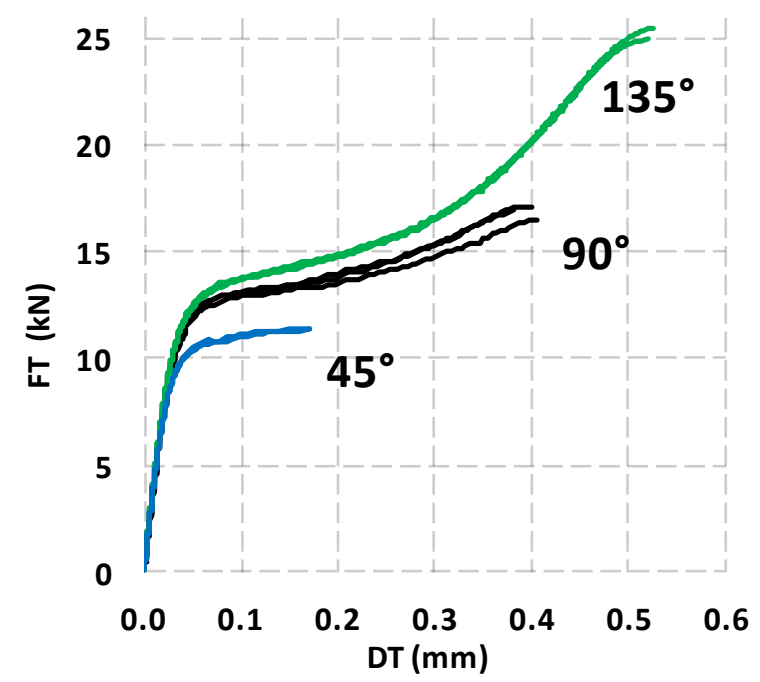

(b)

Fig. 3. Modified Arcan test results for: (a) Tension $\left(0^{\circ}\right)$, normal part of tension-shear $\left(45^{\circ}\right)$, normal part of compression-shear $\left(135^{\circ}\right)$ and (b) Shear $\left(90^{\circ}\right)$, tangential part of tension-shear $\left(45^{\circ}\right)$, tangential part of compression-shear $\left(135^{\circ}\right)$.

d. 3D elastic-plastic constitutive model: Mahnken-Schlimmer type model

Maurice et al. implemented a Mahnken-Schlimmer type model in Abaqus ${ }^{\mathrm{TM}}$ [26]. It is based on 4 equations inspired from the work of Mahnken and Schlimmer [25]. This model is written under the non-associated formalism and depends on the hydrostatic stress.

The yield surface, $f$, is defined by:

$$
f=\sqrt{\sigma_{V M}^{2}+a_{1} Y_{0} p+a_{2} p^{2}}-Y
$$

Where $\sigma_{\mathrm{VM}}$ is the von Mises equivalent stress, $\mathrm{p}$ the hydrostatic stress defined when the stress tensor $\underline{\underline{\sigma}}$ is divided into a deviatoric component $\underline{\underline{S}}$ and a hydrostatic component. $\underline{\underline{I d}}$ is the third order identity tensor: 


$$
\underline{\underline{\sigma}}=\underline{\underline{S}}+p \underline{\underline{I d}} \quad \text { (3.1) } \quad \sigma_{V M}=\sqrt{\frac{3}{2} \underline{\underline{S}}: \underline{\underline{S}}} \quad \text { (3.2) } \quad p=\frac{1}{3} \operatorname{tr}(\underline{\underline{\sigma}})
$$

To determine the yield surface, three parameters need to be identified: $Y_{0}$ which corresponds to the von Mises stress at the elastic-plastic limit in pure shear and $a_{1}$ and $a_{2}$ which govern the elliptic shape of the yield surface in the von Mises-hydrostatic stress (Mises-p) plane.

The hardening is given by:

$$
Y=Y_{0}+q\left(1-e^{-b e_{v}}\right)+H e_{v}
$$

Where $q, b$ and $H$ are the three parameters to be identified. The internal strain-like variable (equivalent plastic strain) $e_{v}$, is defined by the equation:

$$
e_{v} Y_{0}=\underline{\underline{\sigma}}: \dot{\underline{\varepsilon}}^{p}
$$

In his PhD, Maurice [33] defined a flow rule, F, which is slightly different from the one proposed by Mahnken and Schlimmer. It includes a dissymmetry between positive and negative hydrostatic stresses:

$$
\begin{aligned}
& F=\sqrt{{\sigma_{V M}}^{2}+a_{2}{ }^{*} p^{2}}-Y \text { when } \mathrm{p} \geq 0 \\
& F=\sqrt{{\sigma_{V M}}^{2}+a_{3}{ }^{*} p^{2}}-Y \text { when } \mathrm{p} \leq 0
\end{aligned}
$$

Where $\mathrm{a}_{2}{ }^{*}$ and $\mathrm{a}_{3}{ }^{*}$ are the two parameters to identify. They represent the shape of half-ellipses in the Mises-p plane. The origin of the dissymmetry comes from experimental observations: the ratio between tangential and normal displacements taken as absolute values and in the plastic part are quite different in tension-shear and compression-shear. A symmetric flow rule $\left(a_{2}{ }^{*}=a_{3}{ }^{*}\right)$, does not allow this behaviour to be described. That is why a dissymmetry was introduced. It allows a better description of the behaviour in compression-shear, a loading rarely explored in the literature.

The inelastic strain behaviour is then given by a classical normal rule between the plastic strain tensor $\left(\underline{\underline{\varepsilon}}^{p}\right)$ and the stress tensor $(\underline{\underline{\sigma}})$ as:

$$
d \underline{\underline{\varepsilon}}^{p}=d \lambda \frac{\partial F}{\partial \underline{\underline{\sigma}}}
$$

To conclude, the identification of the model requires the identification of 8 parameters: $Y_{0}, a_{1}, a_{2}, q$, b, $\mathrm{H}, \mathrm{a}_{2}{ }^{*}$ and $\mathrm{a}_{3}{ }^{*}$, plus the Young's modulus and the Poisson's ratio (E and $\mathrm{v}$ ).

e. Inverse identification procedure for the unaged state

The experimental database obtained with the modified Arcan test was used for the parameter identification. As the stress state is non-uniform in a modified Arcan joint [34], it is not possible to directly extract a stress-strain curve and an inverse identification technique is required. A sequential inverse identification procedure, fully detailed in [26], was performed in four steps. 


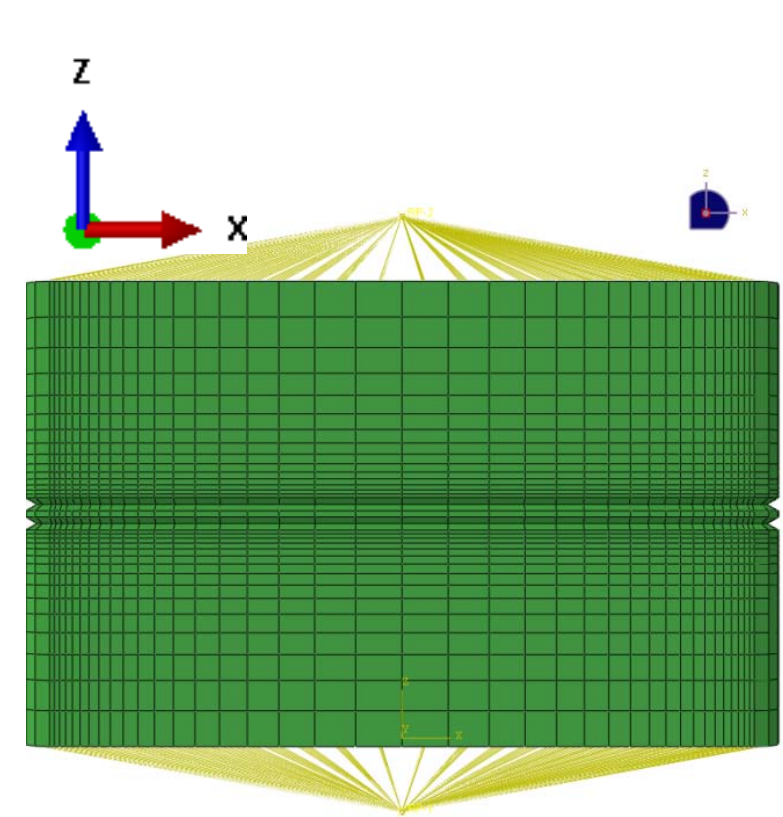

(a)

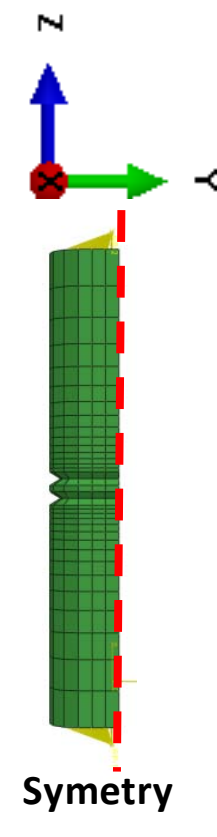

(b)

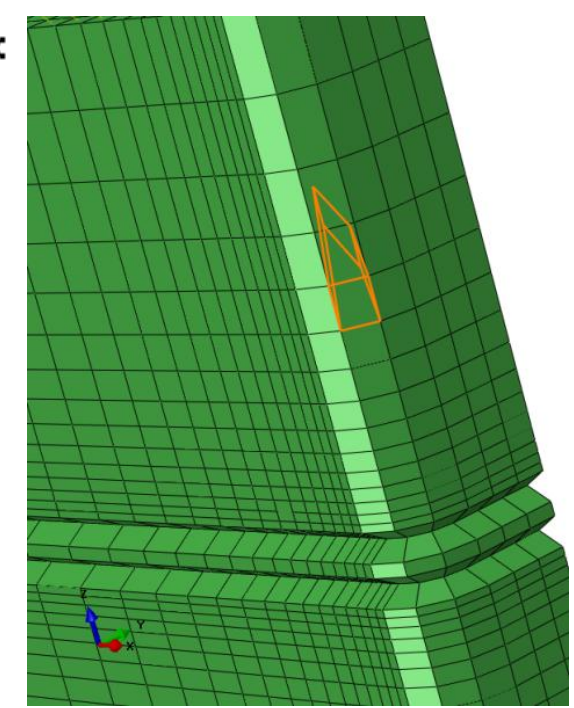

(c)

Fig. 4. 3D-modeling of the modified Arcan test suited to an inverse identification: (a) Front view, (b) Side view and (c) Zoom close to the beaks.

The inverse identification uses numerical finite-element simulation software, (Abaqus ${ }^{\mathrm{TM}}$ ) coupled to an optimisation software (Boss Quattro ${ }^{\mathrm{TM}}$ [35]). Abaqus simulates the response of the modified Arcan test, with an initial set of Mahnken-Schlimmer parameters. The relative displacement is computed via a Python ${ }^{T M}$ script. It corresponds exactly to the displacement retrieved experimentally during the post-processing steps. The simulated force-displacement curve is then compared to the experimental curve. A least-squares error is computed. This error is input to Boss Quattro ${ }^{\mathrm{TM}}$ that uses its optimisation algorithms. Finally it generates the best set of parameters, which is the set that minimises the error. The finite-element model of the modified Arcan sample used in Abaqus is shown in Fig. 4. The large number of iterations in the optimisation procedure makes it necessary to use a rough model. Therefore the model is made of 9000 C3D8 and 400 C3D6 elements, with 1 element in the thickness direction of the adhesive. This gives sufficiently accurate results for a reasonable calculation time of 20 minutes (4 CPUS, 3.1GHz). Two "kinematic couplings" are applied, one linking the lower surface to a lower point and a second linking the upper surface to a upper point (Fig. 4a). A force is applied to these driving points to simulate the Arcan test.

ii. Identification procedure

- Direct identification of Young's modulus and Poisson's ratio using all the experimental curves.

- Direct identification of the yield function with the results of all the loading directions.

The aim is to determine $Y_{0}, a_{1}$ and $a_{2}$. It is known from previous studies [26, 34] that the end of linearity observed on the modified Arcan curves corresponds to first yielding in the centre of a sample. The force at the end of linearity can be extracted from the curves. An elastic finite-element calculation of a modified Arcan sample loaded with this force can then be performed. Retrieving the von Mises stress and the hydrostatic stress in the central element of the model allows a point on the yield surface in the (Mises-p) plane to be obtained. Repeating this operation for the four loading 
directions $\left(0,45,90\right.$ and $\left.135^{\circ}\right)$ gives four points on the yield surface. An ellipse can then be fitted by calculating a least squares error. It gives the $Y_{0}, a_{1}$, and $a_{2}$ parameters.

- Inverse identification of the hardening function with the results in shear.

The aim is to determine $\mathrm{q}, \mathrm{b}$ and $\mathrm{H}$. In shear loading $\left(90^{\circ}\right)$ the hydrostatic stress is zero, the behaviour is independent of $\mathrm{a}_{2}{ }^{*}$ and $\mathrm{a}_{3}{ }^{*}$ : the flow direction does not change and the hardening function can easily be identified by an inverse identification on the shear results.

\begin{tabular}{|l|c|}
\cline { 2 - 2 } \multicolumn{1}{l|}{} & Unaged parameters \\
\hline $\mathbf{E}(\mathrm{MPa})$ & 1650 \\
\hline $\mathbf{v}$ & 0.34 \\
\hline $\mathbf{a}_{\mathbf{1}}$ & 0.64 \\
\hline $\mathbf{a}_{\mathbf{2}}$ & 0.38 \\
\hline $\mathbf{Y}_{\mathbf{0}}(\mathrm{MPa})$ & 35.9 \\
\hline $\mathbf{q}(\mathrm{MPa})$ & 9.7 \\
\hline $\mathbf{b}$ & 60 \\
\hline $\mathbf{H}(\mathrm{MPa})$ & 17 \\
\hline $\mathbf{a}_{\mathbf{2}}{ }^{*}$ & 0.7 \\
\hline $\mathbf{a}_{\mathbf{3}}{ }^{*}$ & 0.05 \\
\hline
\end{tabular}

(a)

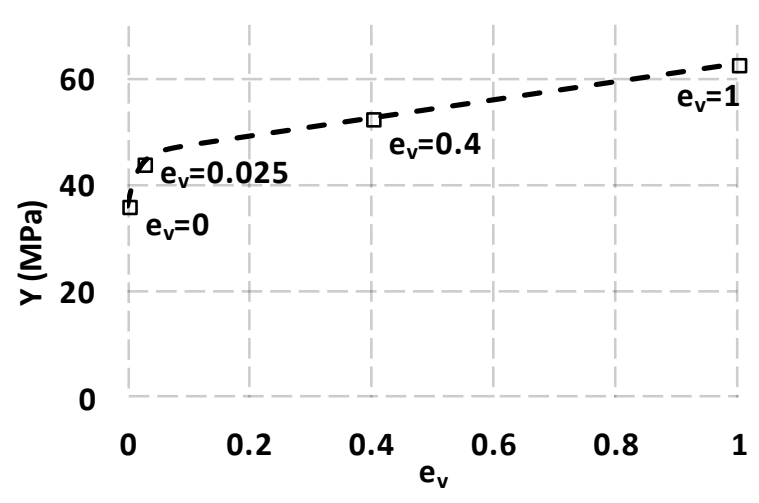

(c)

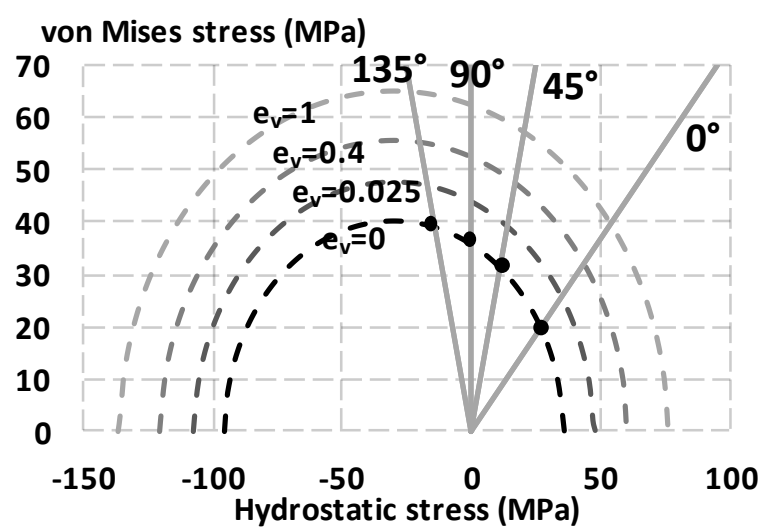

(b)

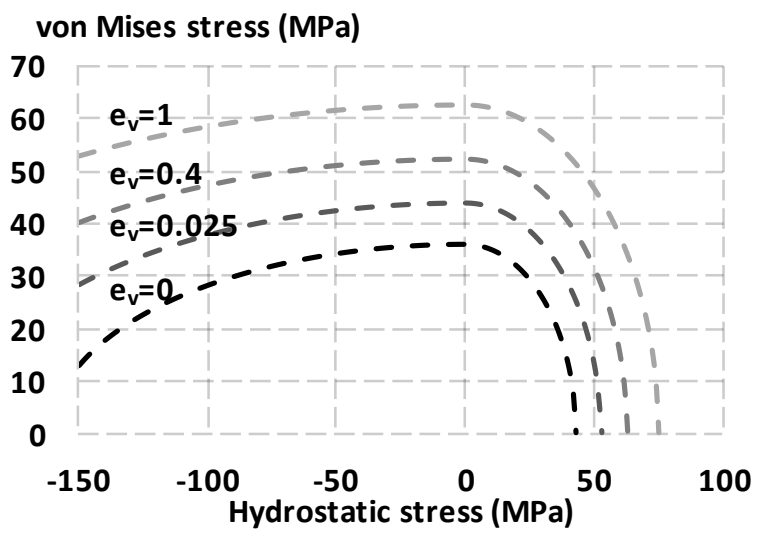

(d)

Fig. 5. Results from the identification of the Mahnken-Schlimmer type model via the modified Arcan test, for several degrees of hardening $\left(e_{v}=0,0.025,0.4,1\right)$ : (a) Summary of parameters, (b) Yield surface, (c) Hardening function and (d) Flow surface.

- Inverse identification of the flow rule on the tension-shear and compression-shear curves.

$a_{2}{ }^{*}$ is determined by inverse identification on the tension-shear results and $a_{3}{ }^{*}$ is determined by inverse identification on the compression-shear results.

The sequential identification procedure cannot ensure the uniqueness of the solution. However, the aim is to determine a set of parameters that describe the behaviour observed globally in all the loading directions. Particular attention is paid to determining logical and coherent parameters and avoiding problems of local minima.

Following these steps, it is possible to obtain the parameters of the Mahnken-Schlimmer model, summarised in Fig. 5a. In Fig. 5b, 5c and $5 \mathrm{~d}$ are given respectively the identified yield surface, the hardening function and the flow rule. 
The results of the inverse identification are superimposed on experimental results in Fig. 6 . The model appears to be well suited to describe the behaviour of adhesive joints, except in tension $\left(0^{\circ}\right)$ where the model shows a slight limitation in the plastic part description.

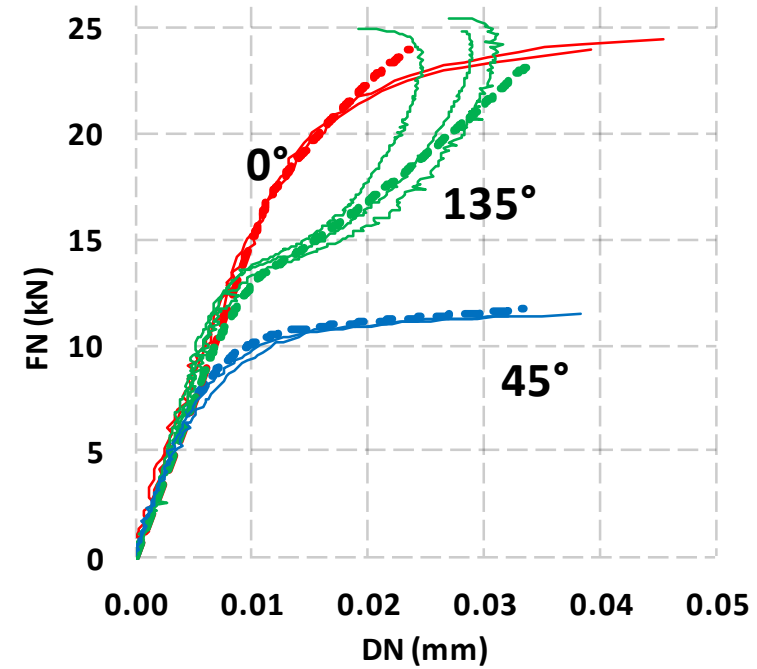

(a)

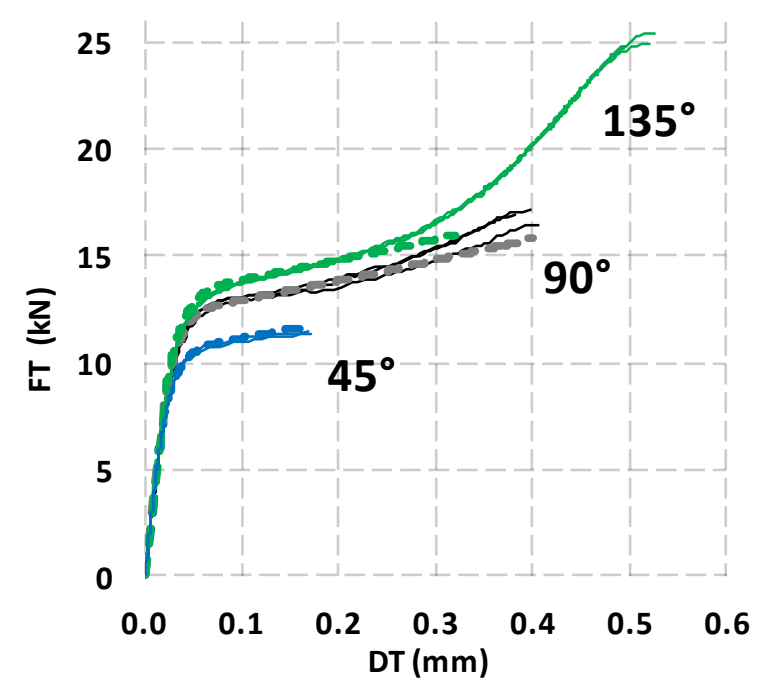

(b)

Fig. 6. Comparison of the model identified (dotted lines) and the experimental results (straight lines): (a) Tension $\left(0^{\circ}\right)$, normal part of tension-shear $\left(45^{\circ}\right)$, normal part of compression-shear $\left(135^{\circ}\right)$ and (b) Shear $\left(90^{\circ}\right)$, tangential part of tension-shear $\left(45^{\circ}\right)$, tangential part of compression-shear $\left(135^{\circ}\right)$.

To summarise, all the methods were set up to identify a constitutive model that describes the behaviour of adhesives in an assembly. The parameters of the Mahnken-Schlimmer type model were determined, for an unaged state. It is then possible to integrate the moisture effect in the model for an assembly exposed to humid aging.

3. Integration of the humid aging effect in the constitutive model identified

a. Identification of the diffusion laws : gravimetric study

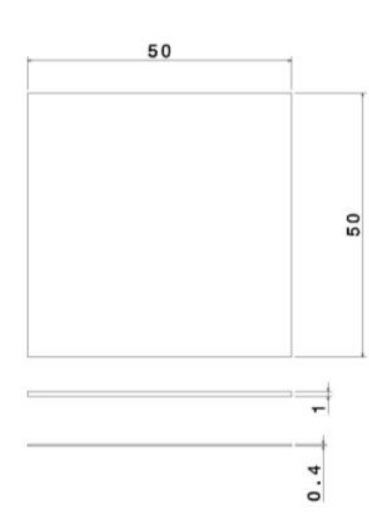

(a)

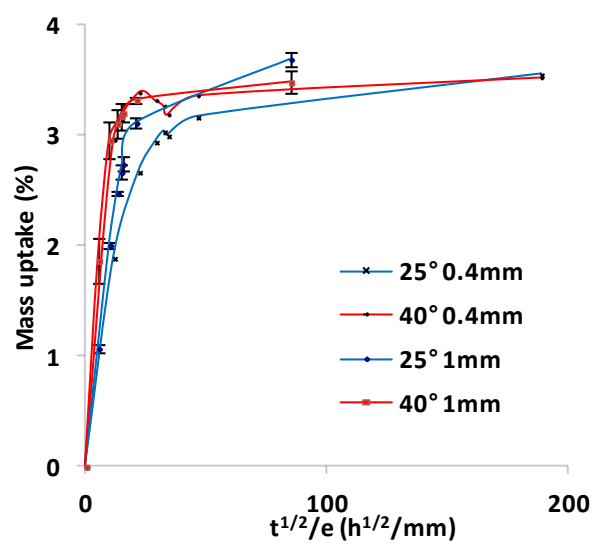

(b)

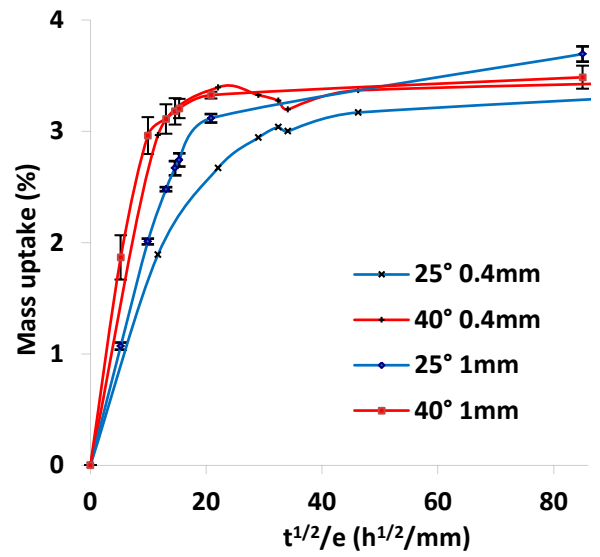

(c)

Fig. 7. Gravimetric analysis: (a) Bulk sample geometry, (b) Mass uptake in sea water for 25 and $40^{\circ} \mathrm{C}$ immersion, for 0.4 and $1 \mathrm{~mm}$ thicknesses and (c) Zoom of the Mass uptake for short times. 
To predict the influence of humid aging on the mechanical behaviour of an adhesive in an assembly, it is necessary to know the kinetics of moisture diffusion in the adhesive. These are determined by gravimetry. The aim is to periodically weigh square bulk adhesive samples in a humid environment to measure the mass uptake.

The sample dimensions were 50*50 $\mathrm{mm}^{2}$, for two thicknesses: 0.4 and $1 \mathrm{~mm}$ (Fig. 7). They were immerged in continuously renewed natural sea water pumped from the Brest (West of Brittany) Estuary as described in [18] and at a controlled temperature of 25 and $40^{\circ} \mathrm{C}$. In Fig. 7 the water mass uptake is given as a percentage plotted versus $\mathrm{t}^{1 / 2}$ divided by $\mathrm{e}$. Where $\mathrm{t}$ is the time in hours and $\mathrm{e}$ the thickness in millimetres. The mass uptake is $\left(w_{t}-w_{0}\right) / w_{0} . w_{t}$ and $w_{0}$ are respectively the weights at time $t$ and initially.

To a first approximation the curves are characteristic of Fickian diffusion: a first linear part and then a stabilisation at a saturation mass. This diffusion can be modelled by a Fickian law [36]:

$$
\frac{w_{t}}{w_{\infty}}=1-\frac{8}{\pi^{2}} \sum_{n=0}^{\infty} \sum_{m=0}^{\infty} \sum_{p=0}^{\infty} \frac{1}{(2 n+1)^{2}(2 m+1)^{2}(2 p+1)^{2}} \exp \left[-D \cdot \pi^{2} t\left(\frac{(2 n+1)^{2}}{4 e^{2}}+\frac{(2 m+1)^{2}}{4 L^{2}}+\frac{(2 p+1)^{2}}{4 h^{2}}\right)\right\rfloor
$$

Where $w_{\infty}$ is the weight at saturation, $\mathrm{D}$ is the diffusion coefficient, $\mathrm{e}, \mathrm{L}$ and $\mathrm{h}$ are respectively the half-thickness, half-length and half-width.

The $\mathrm{Tg}$ of the unaged adhesive is about $70^{\circ} \mathrm{C}$ and decreases during wet aging. The aging temperature was chosen to be $40^{\circ} \mathrm{C}$ for accelerated aging. The diffusion coefficient of the Fickian law was extracted from the curves. It is $D=6.8^{*} 10^{-13} \mathrm{~m}^{2} / \mathrm{s}$ at $40^{\circ} \mathrm{C}$. This value is similar to those obtained by Bua et al. [13] and Bordes et al.[18].

\section{b. Integration in a numerical diffusion model}

As the diffusion law was identified and the diffusion coefficient was determined, it was possible to determine the concentration at any point and at any aging time in an adhesive layer. Therefore it was possible to model the moisture diffusion in an adhesively bonded assembly exposed to humid aging. This was achieved using the finite-element software Abaqus. The diffusion in a modified Arcan sample joint was simulated. A normalized water uptake was applied on the free edges of the adhesive layer of a modified Arcan specimen. This is shown in Fig. 8a where half a sample is modelled. The diffusion coefficient identified at $40^{\circ} \mathrm{C}$ was introduced. The concentration profiles were then available for any aging time. 


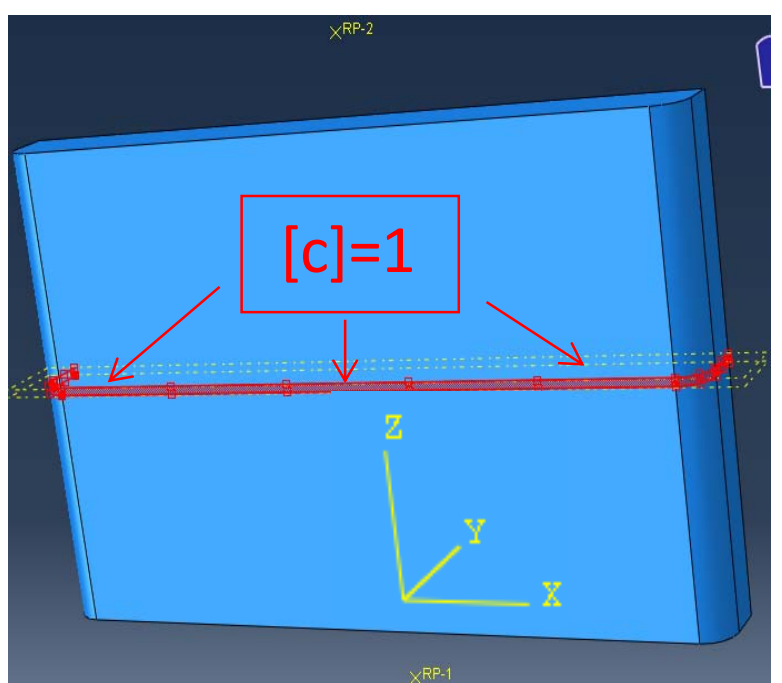

(a)

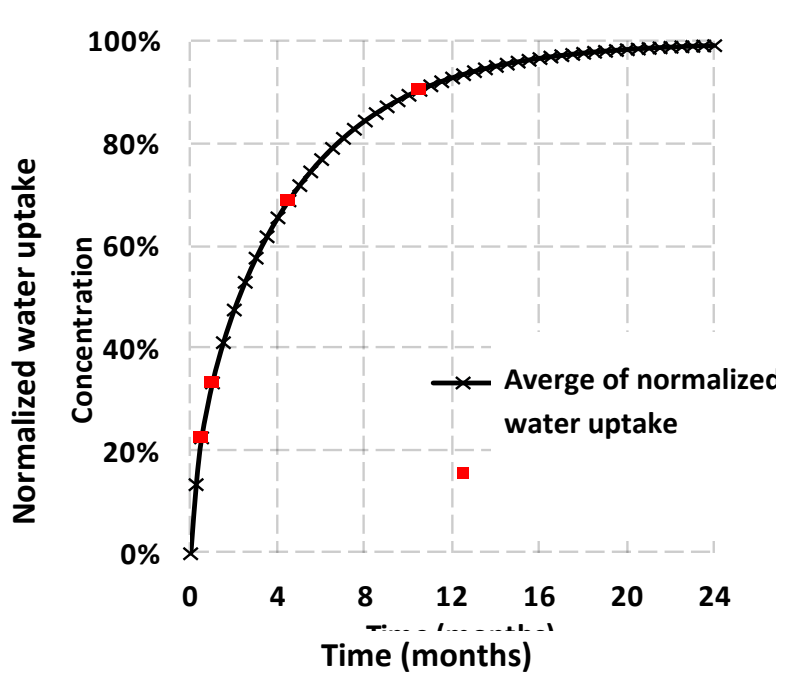

(b)
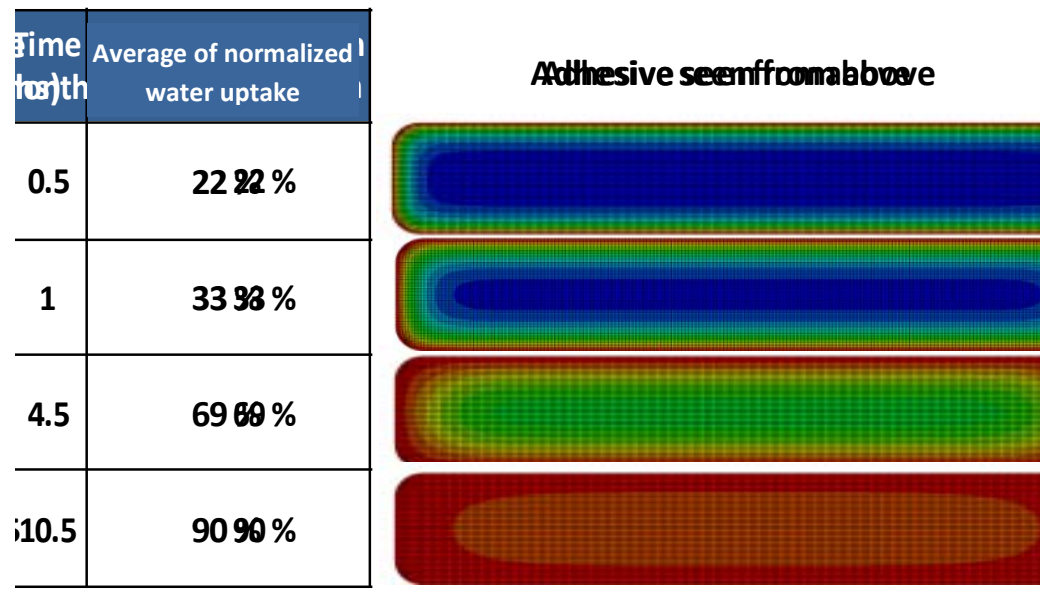

(c)

Fig. 8. Simulation of water diffusion in a modified Arcan sample: (a) Finite-element model, (b) Normalized water uptake and (c) Normalized water uptake profiles for the aging times selected.

During humid aging, the moisture uptake absorbed in an adhesive is time and space dependant. It evolves during aging, giving different concentration gradients. Thus for a given aging time the problem is only space dependent. To analyse the effect of humid aging via modified Arcan tests, it is necessary to have an experimental database including several aging times. The number of aging times should be sufficient to accurately identify the aging effect. An experimental Arcan campaign requires 12 samples per aging time. Four aging times plus the unaged state were chosen, as a good compromise between accuracy and quantity of samples. Fig. 8c presents the normalized water uptake profiles in the modified Arcan adhesive layer (seen from above) corresponding to the unaged state $\left(t_{0}\right)$ and four aging times $\left(t_{1}, t_{2}, t_{3}, t_{4}\right)$. They represent respectively 0.5 month, 1 month, 4.5 months' and 10.5 months' aging. These aging times will be used later for the aging of modified Arcan samples. They were chosen as they correspond to $22 \%, 33 \%, 69 \%$ and $90 \%$ of the normalized water uptake (Fig. 8b). These concentration profiles were estimated to be sufficient to obtain an accurate analysis of the influence of aging.

\section{c. Modified Arcan tests on aged samples}

The modified Arcan samples were manufactured according to the same procedure as before and cured (Fig. 9a). They were aged in sea water tanks at $40^{\circ} \mathrm{C}$ (Fig. 9b) during the four aging times selected. After aging, they were tested according to the defined procedure. The results are presented 
in Fig. 10 and superimposed on the results obtained for the unaged state. The evolution of the behaviour with the aging time seems logical: the mechanical properties decrease during aging. The scatter in the results is very low, so they are suited to inverse identification.

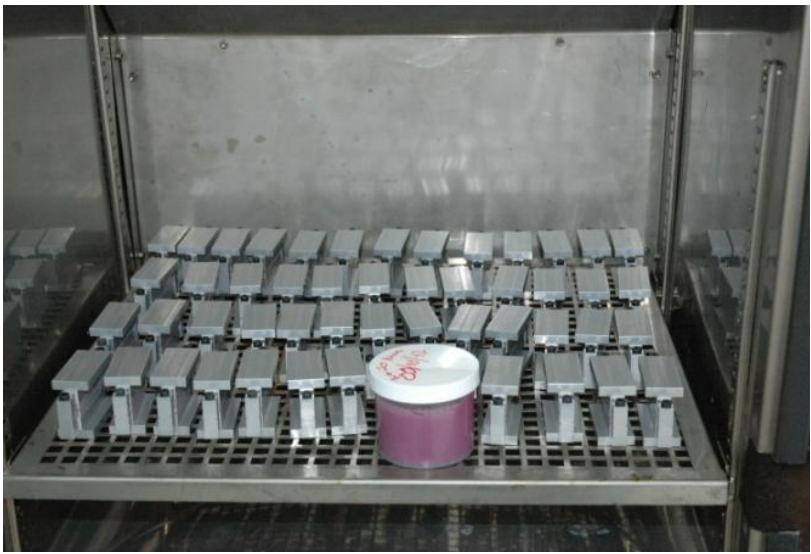

(a)

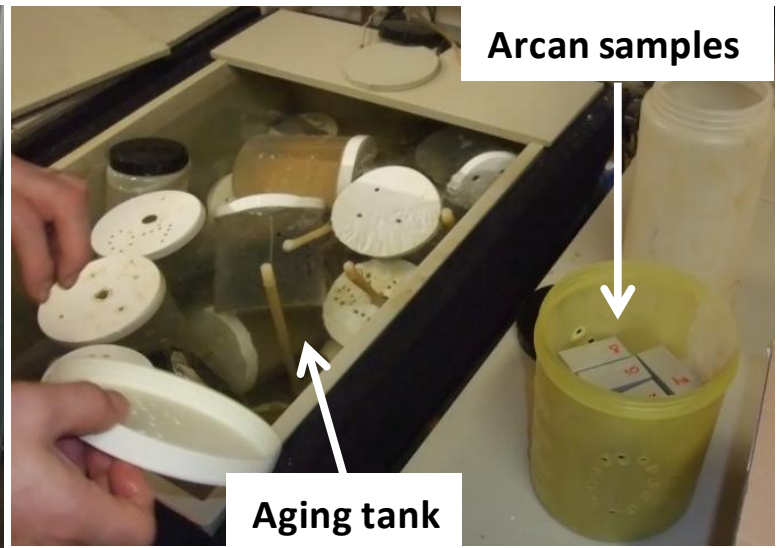

(b)

Fig. 9. Modified Arcan samples: (a) Curing in the oven and (b) Aging in sea water tanks.

The fracture surfaces are shown in Fig. 11. In tension, the failure is fully cohesive for the unaged state. Then it becomes partially cohesive during aging. But at the last aging time it is again fully cohesive. This evolution seems to indicate that the interface is slightly affected by humid aging in tension. However, it is not clear enough to conclude on a real interfacial degradation. In the other loading directions, the failure is mainly adhesive and does not reveal any evolution during aging. 


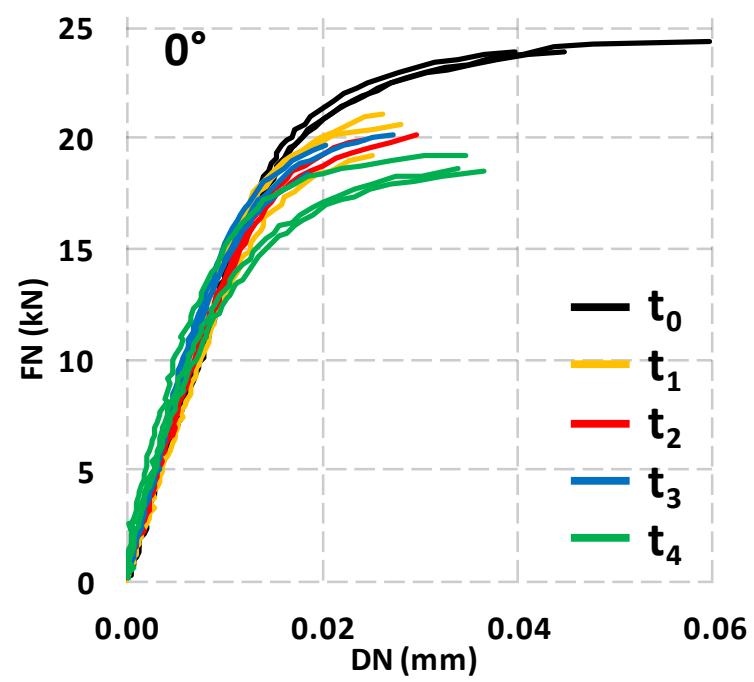

(a)

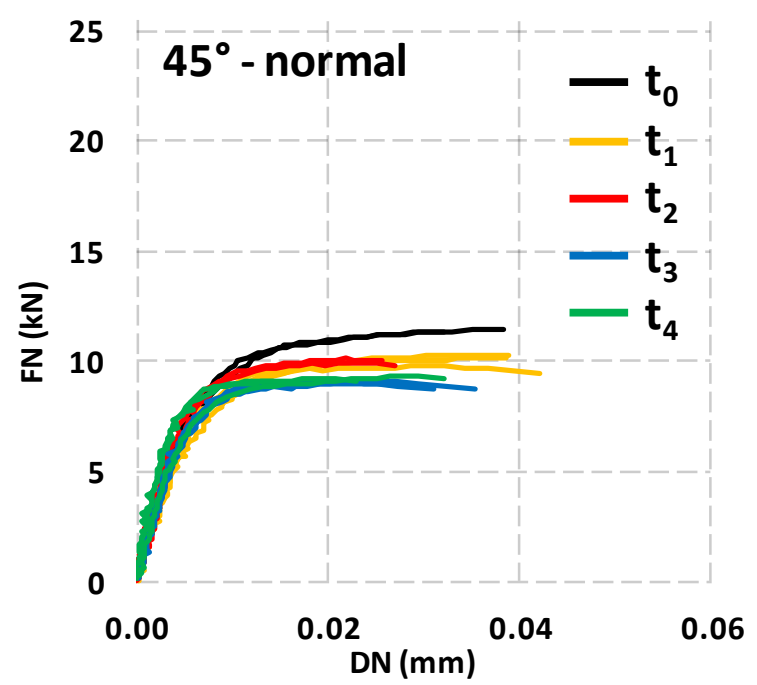

(c)

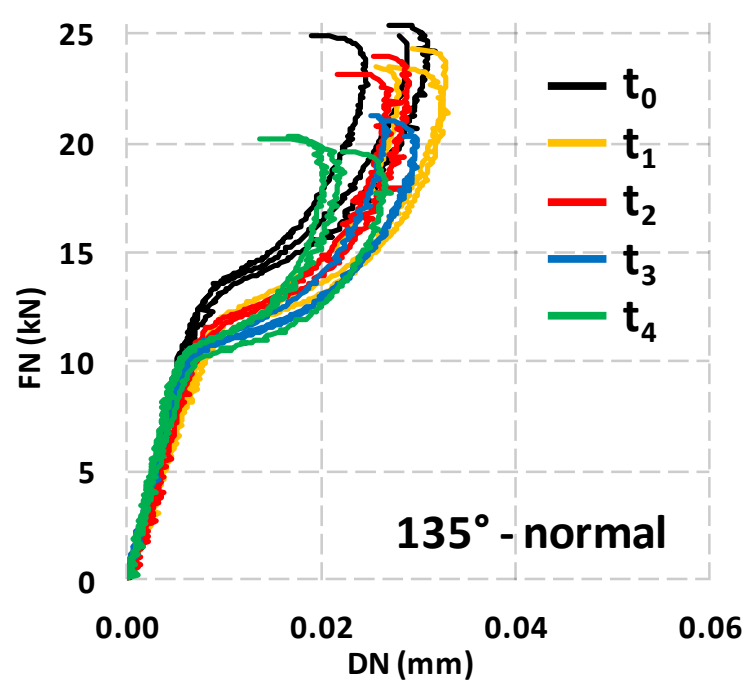

(e)

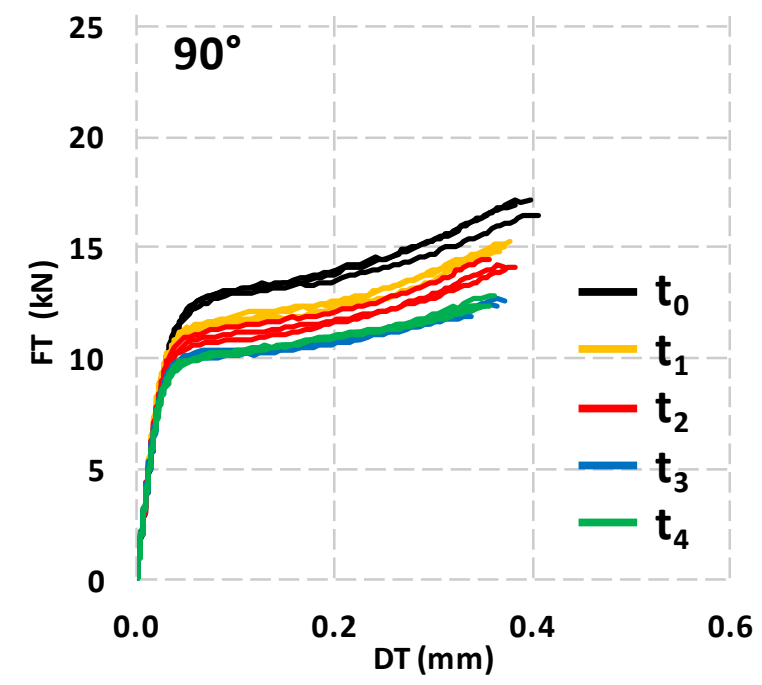

(b)

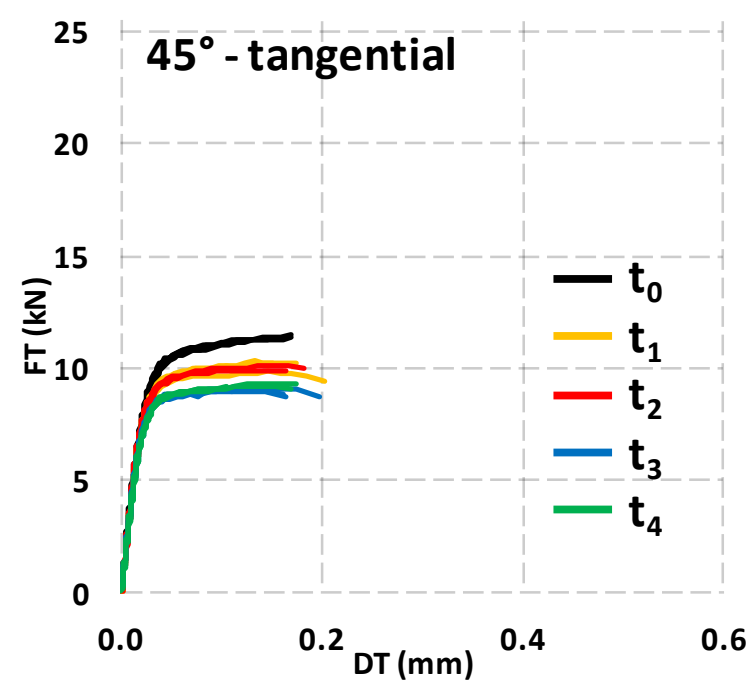

(d)

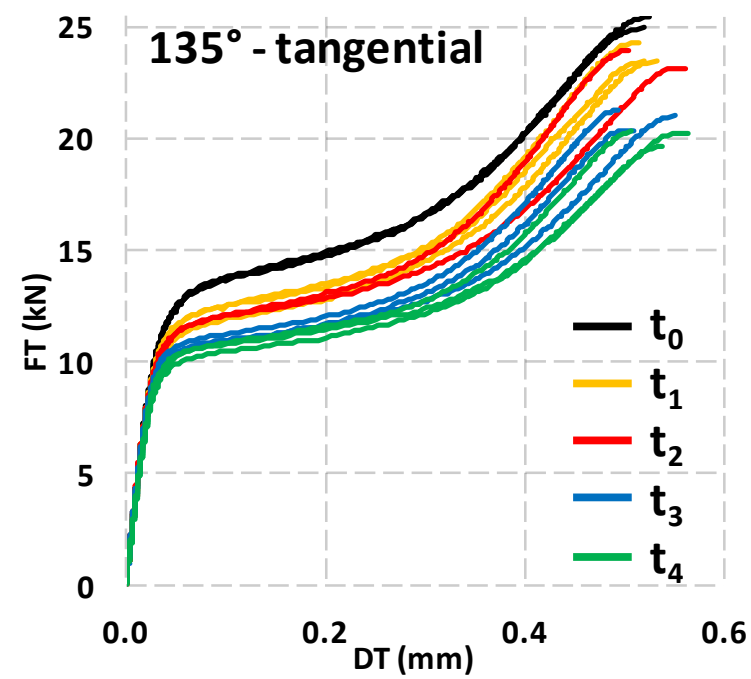

(f)

Fig. 10. Modified Arcan test results for four aging times: (a) $0^{\circ}$, (b) $90^{\circ}$, (c) $45^{\circ}$-normal, (d) $45^{\circ}$ tangential, (e) $135^{\circ}$-normal, et (f) $135^{\circ}$-tangential. 

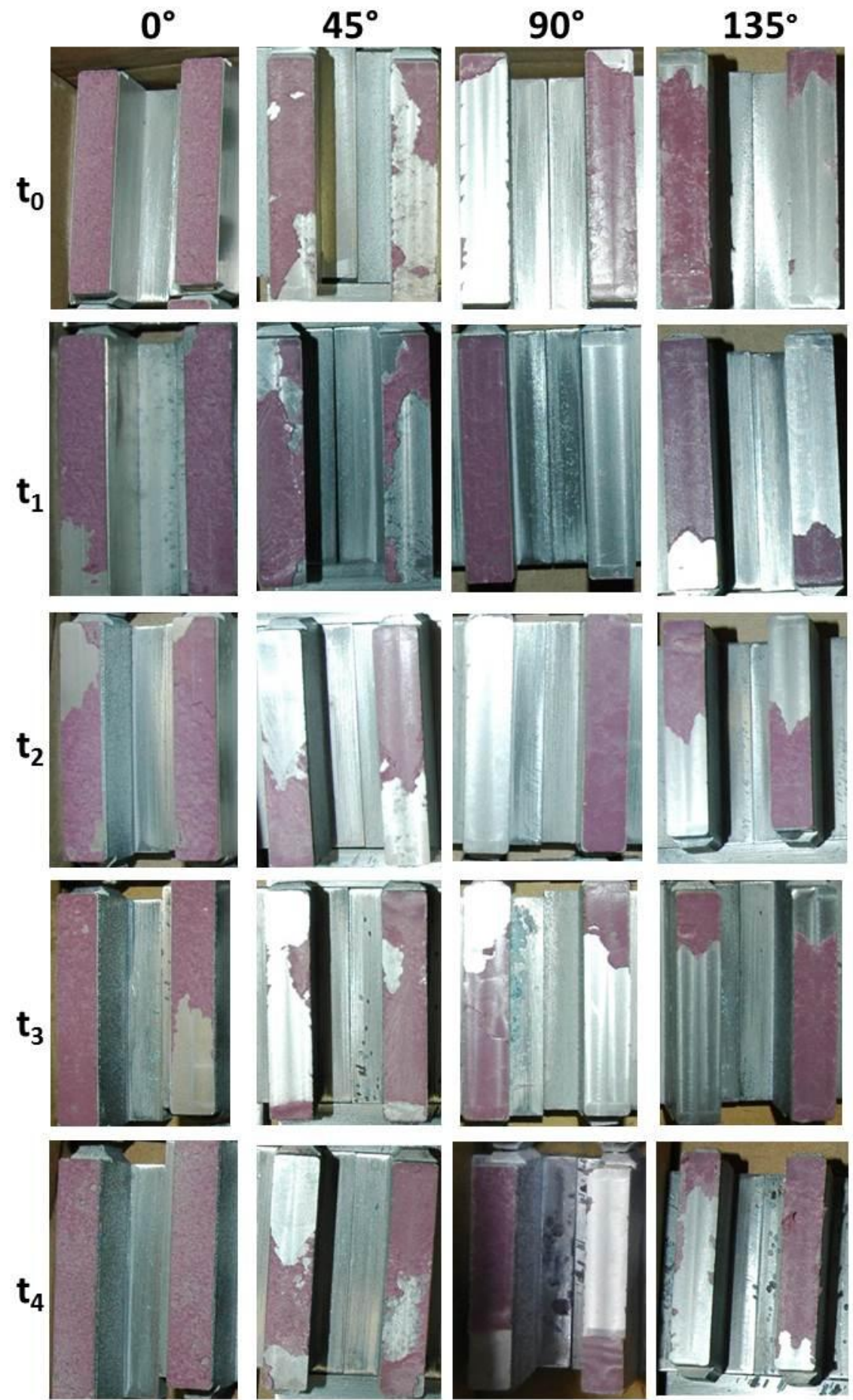

Fig. 11. Failure profiles of the modified Arcan test during sea water aging.

The forces, DN and DT at failure are given in Fig. 12. The means values are given along with the standard deviations. For the forces and the tangential displacements (DT), the values globally decrease during humid aging. No clear conclusions can be drawn from the normal displacements (DN). However, this direction is very sensitive to defects and the displacements are about 10 times lower than the tangential displacements. 


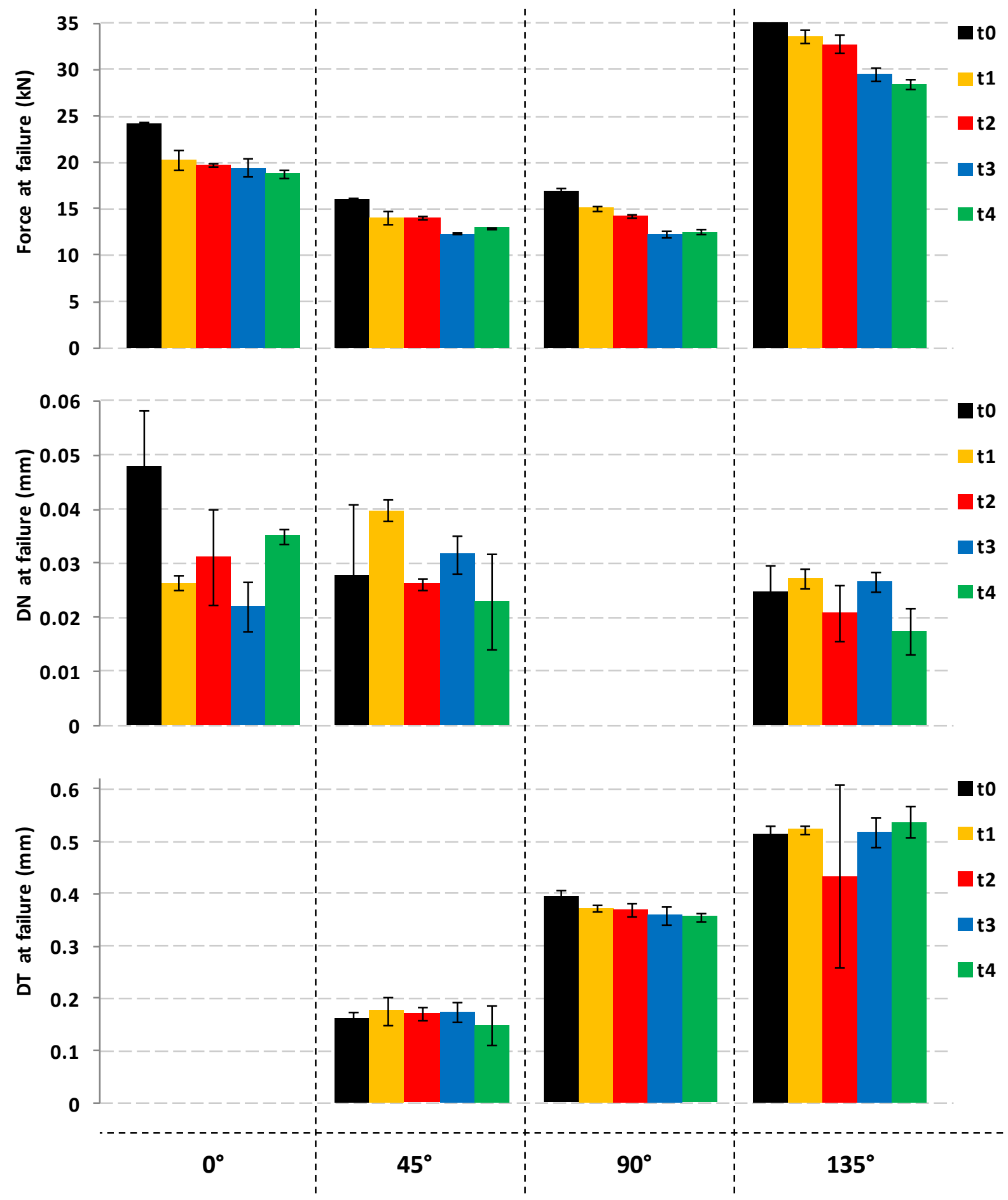

Fig. 12. Force, DN and DT at failure for $t_{0}$ to $t_{4}$ for each loading direction: Mean value and standard deviation.

d. Definition of a procedure for the global inverse identification of the model as a function of the normalised water concentration

To identify the unaged state, an inverse identification technique was again necessary to overcome the non-uniformity of the stress state in the adhesive. When studying aging, water ingress causes a water concentration gradient in the adhesive. As this concentration directly impacts the mechanical properties, these properties are non-uniform in the adhesive. This makes the study more complicated. Inverse identification strategies are still necessary to identify the behaviour as a function of the concentration and several aging times must be used to consider the different 
concentration profiles in the adhesive. The Mahnken-Schlimmer model used to describe the unaged state is already quite sophisticated. Taking water effect into account would make it more complex. As a result it was preferred to enrich it with a model as simple as possible rather than a model including all the physical changes.

A global inverse identification technique is proposed (Fig. 13). It is based on the techniques used for the unaged state, but here "global" means that several aging times are considered in the identification. The input data are the Mahnken-Schlimmer parameters identified for the unaged state, the four concentration profiles simulated and the modified Arcan test results for the same aging times. The key point is to propose a hypothesis for the change in the model parameters with the water concentration. This can be based on the experimental data: linear, exponential, etc. For example the evolution can be:

Where, $p$ is the parameter

$$
p(c)=p_{0}-\alpha . c
$$

$\mathrm{c}$ is the water concentration

$\mathrm{p}_{0}$ is the unaged parameter

$\alpha$ is the parameter to optimise

With these mechanical parameters depending on the concentration, the concentration profiles already simulated can be used to perform a diffusion-mechanics coupling calculation. It allows a simulation using Abaqus $^{\mathrm{TM}}$ of the response of the modified Arcan test for the four aging times. For each aging time, the response can be compared to the experimental Arcan data and a least squares error can be calculated. The errors are summed for each aging time. At the end, a global error is defined and optimisation software (Boss Quattro ${ }^{\mathrm{TM}}$ ) is used to generate the best set of parameters, which minimises the global error.

The identification procedure used for the unaged state is modified here:

- Identification of the hardening function

This is performed with a global inverse identification on the shear $\left(90^{\circ}\right)$ results. $\mathrm{q}, \mathrm{b}, \mathrm{H}$ and $\mathrm{Y}_{0}$ have to be defined. The shear results are used because the hydrostatic stress is zero, then the results are independent from $a_{1}, a_{2}, a_{2}{ }^{*}$ and $a_{3} *$.

- First approximation of the yield function

In the tangential directions, the flow parameters $\mathrm{a}_{2}{ }^{*}$ and $\mathrm{a}_{3}{ }^{*}$ have a very small influence. A first approximation of the yield function can then be obtained with a global inverse identification on the tangential results of tension-shear and compression-shear $\left(45^{\circ}\right.$ and $\left.135^{\circ}\right)$. This provides a good approximation of $\mathrm{a}_{1}$ and $\mathrm{a}_{2}$.

- Determination of the flow rule

$\mathrm{a}_{2}{ }^{*}$ corresponds to positive hydrostatic stresses, it is therefore identified on $45^{\circ}$ curves, in the normal direction via a global inverse identification. In the same way, $a_{3}{ }^{*}$ corresponds to negative hydrostatic stresses and a global inverse identification is performed on the $135^{\circ}$ curves, in the normal direction. 


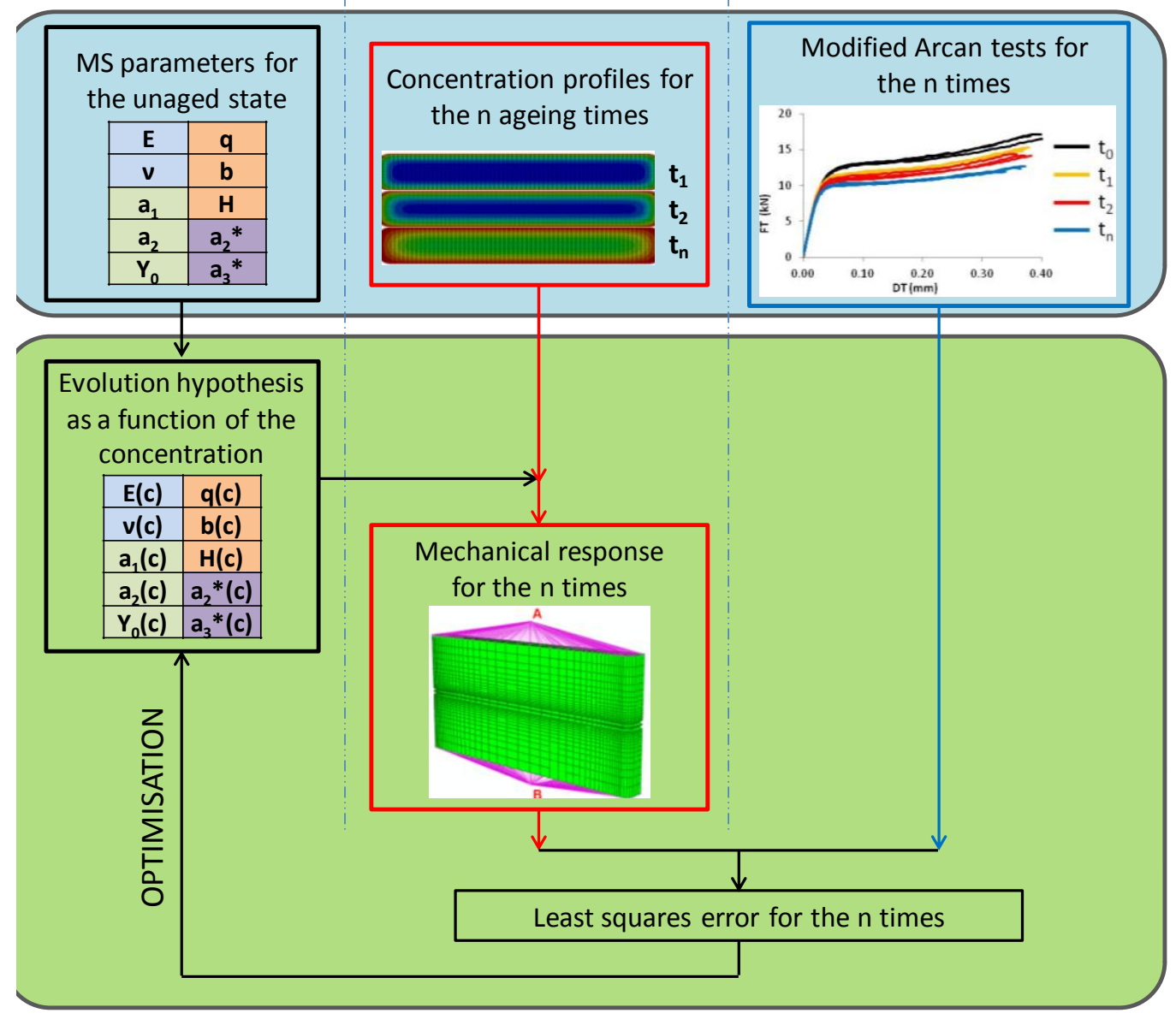

Fig. 13. Global inverse identification procedure.

- Precise identification of the yield function

A verification is made at $0^{\circ}$ (tension). If the behaviour is not correctly described, a new identification of $a_{1}$ and $a_{2}$ is realised, this time considering all the loading directions $\left(0,45,90\right.$ and $\left.135^{\circ}\right)$.

If necessary, a second more precise global identification is performed at the end of the procedure. Here again, the uniqueness of the solution cannot be assured.

A first global identification attempt was made to identify the parameters of the model as a function of water concentration. However, it was not possible to describe the behaviour for every aging time. Bulk tensile tests were then carried out, to check if the loss of mechanical properties observed during wet aging was only due to water ingress.

e. Bulk tensile test of aged samples

\section{i. First study at $25^{\circ} \mathrm{C}$ and $40^{\circ} \mathrm{C}$}

Tensile tests were performed on bulk dog-bone samples aged at different times at 25 and $40^{\circ} \mathrm{C}$ in sea water, according to the same procedure as the for unaged state. In Fig. 14a, 14b and 14c are shown respectively manufactured samples, samples aged in sea water tanks for each aging time, 3 samples were extracted from the aging tanks and tested. The results are presented in Fig. 15. 


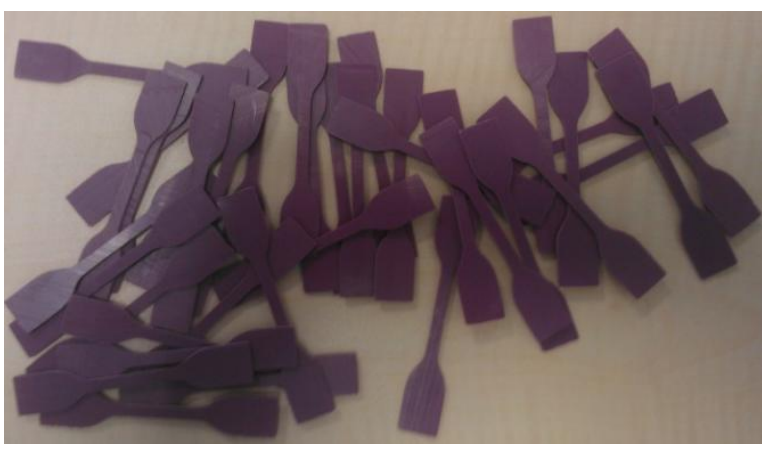

(a)

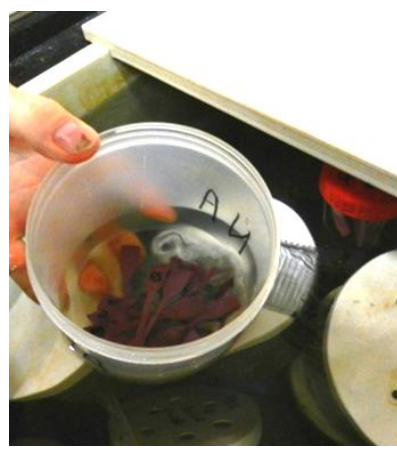

(b)

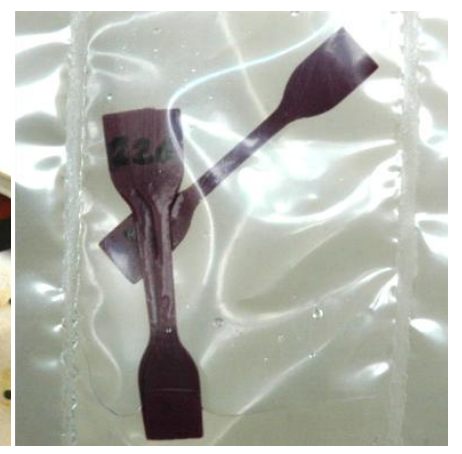

(c)

Fig. 14. Experimental aging procedure: (a) Bulk tensile specimens before aging, (b) Samples in sea water aging tank and (c) Samples kept in sealed plastic bag containing sea water, after aging before testing.At 25 and $40^{\circ} \mathrm{C}$, the curves for several aging times are given in Fig. 15a and 15b. For each configuration only one curve is given on the three samples tested. This allows an easier reading and is justified by the low scatter between the three curves. The unaged state already obtained is superimposed. The aging times considered are presented in Fig. 15c.

From these curves, the tendency is the same for the two aging temperatures: a decrease of the threshold in the mechanical properties appears for the first aging time. Then the properties increase. This increase is progressive at $25^{\circ} \mathrm{C}$ and is already stable at $t_{2}$ at $40^{\circ} \mathrm{C}$. The 25 and $40^{\circ} \mathrm{C}$ curves are compared in Fig. $15 \mathrm{~d}$ and a zoom is realised. The conclusions are that the behaviour at the first aging time is the same for the two temperatures. Then the mechanical properties increase, slowly at $25^{\circ} \mathrm{C}$ and quickly at $40^{\circ} \mathrm{C}$. At $t_{2}$ at $40^{\circ} \mathrm{C}$ and at $t_{5}$ at $25^{\circ} \mathrm{C}$, the behaviour is stable.

This behaviour means that during aging, two phenomena are in competition. The first one is the expected degradation of the adhesive by water ingress. It is visible after the first aging time and makes the mechanical properties decrease. Then a second phenomenon occurs, which causes an increase in mechanical properties. It is much quicker at $40^{\circ} \mathrm{C}$. DSC analyses also reveal the same tendencies for Tg. This second phenomenon appears to involve a slight post-curing of the adhesive.

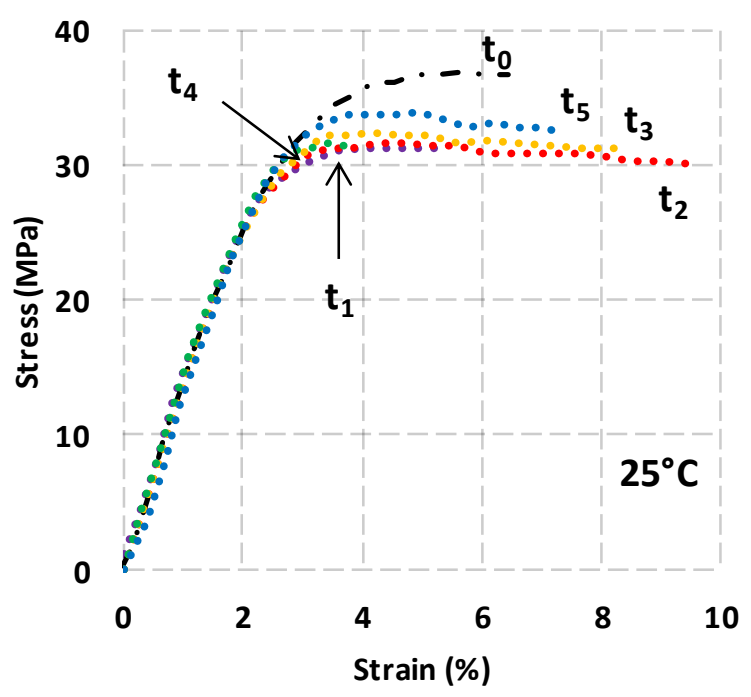

(a)

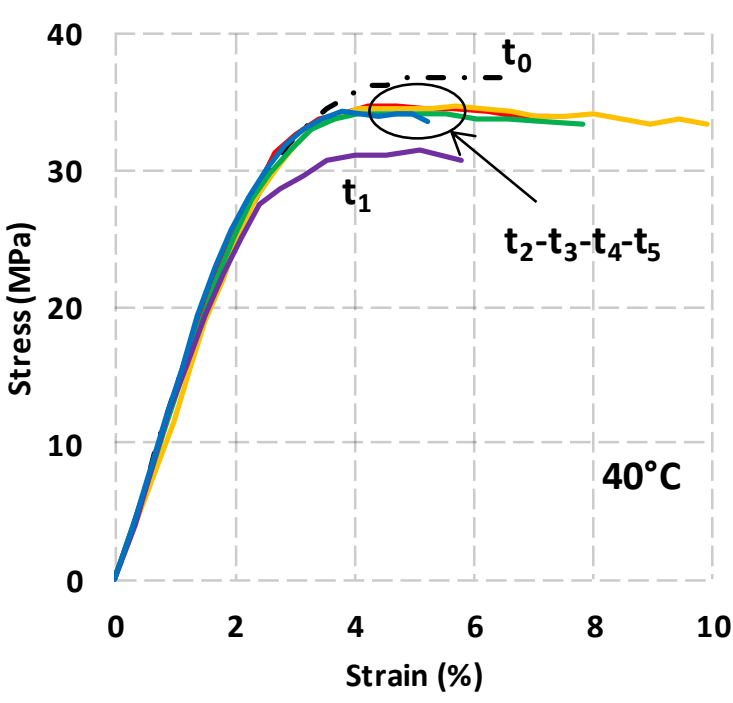

(b) 


\begin{tabular}{|c|c|}
\hline \multicolumn{2}{|c|}{ Aging times } \\
\hline$t_{1}$ & 8 days \\
$t_{2}$ & 26 days \\
$t_{3}$ & 49 days \\
$t_{4}$ & 86 days \\
$t_{5}$ & 427 days \\
\hline
\end{tabular}

(c)

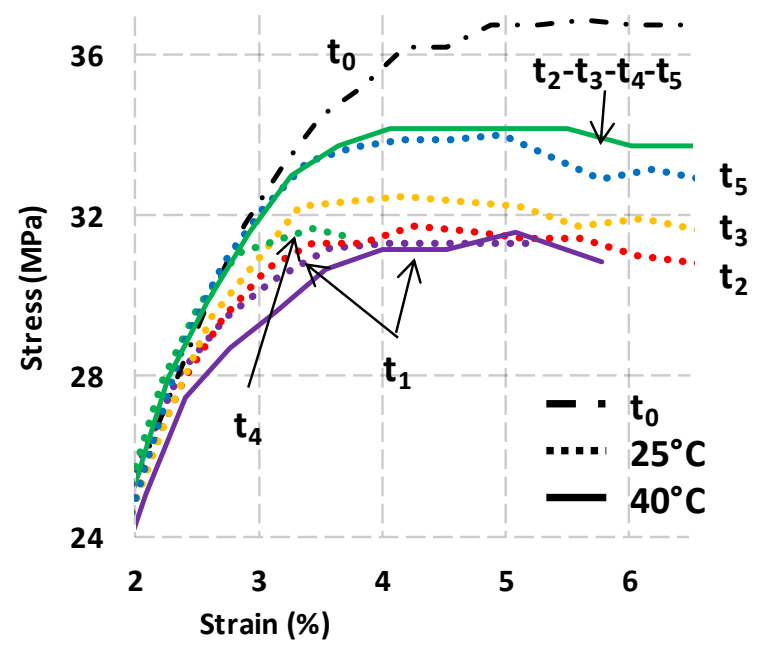

(d)

Fig. 15. Results of tensile tests on aged bulk samples: (a) At $25^{\circ} \mathrm{C}$, (b) At $40^{\circ} \mathrm{C}$, (c) Aging times considered and (d) Superimposition of (a) and (b) and zoom on the plastic part of the curve.

\section{ii. Second study more precise at $40^{\circ} \mathrm{C}$}

As after aging for one month in sea water at $40^{\circ} \mathrm{C}$ the behaviour seems stabilised, two other sets of tests were performed. The first one corresponds to 3 unaged samples that have spent one month more in the oven at $40^{\circ} \mathrm{C}$. The second set of tests corresponds to 3 samples that have spent one month in sea water at $40^{\circ} \mathrm{C}$ followed by one month in the oven at $40^{\circ} \mathrm{C}$. The mass is followed to assure that after this month the samples are dry. These sets of tests are respectively referred to as "Unaged+oven" and "Water+oven" in Fig. 16. They are compared to the samples at $40^{\circ} \mathrm{C} \mathrm{t}_{0}$ (called "Unaged") and the samples at $40^{\circ} \mathrm{C} t_{2}$ (called "Water") from Fig. $16 \mathrm{~b}$.

When the unaged samples that have spent 1 month more in the oven at $40^{\circ} \mathrm{C}$ ("Unaged+oven") are compared to the samples aged 1 month in sea water at $40^{\circ} \mathrm{C}$ and dried 1 month at $40^{\circ} \mathrm{C}$ ("Water+oven"), the curves are superimposed. This means that the effect of sea water (the first phenomenon) is totally reversible. Swelling was estimated from the gravimetric analysis to be $3 \%$ by volume. It is low compared to the other phenomena occurring. The conclusion is that the effect of sea water on the adhesive is essentially plasticization.

When the unaged samples that have spent 1 month more in the oven at $40^{\circ} \mathrm{C}$ ("Unaged+oven") are compared to the unaged samples, the effect of the second phenomenon is highlighted. Indeed after staying one month in the oven (without water) the mechanical properties are improved and $\mathrm{Tg}$ has increased by a couple of degrees. 


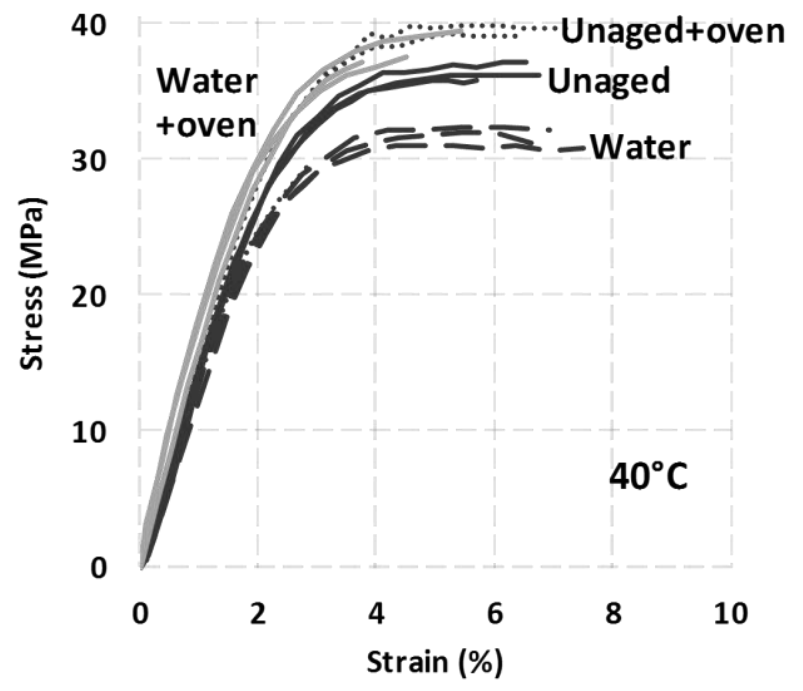

Fig. 16. Second study with bulk tensile tests: 3 unaged samples that have spent 1 month more in the oven at $40^{\circ} \mathrm{C}$ ("Unaged+oven"), 3 samples aged 1 month in sea water at $40^{\circ} \mathrm{C}$ and dried 1 month at $40^{\circ} \mathrm{C}$ ("Water+oven"), Unaged samples ( $\mathrm{t}_{0}$ in Fig. $\left.15(\mathrm{~b})\right)$ and 1 month in sea water at $40^{\circ} \mathrm{C}\left(\mathrm{t}_{2}\right.$ in Fig. 15(b)).

Tensile tests on bulk samples are a quick way to obtain a large amount of information about marine aging effects. The main conclusions here are that:

- Two competitive phenomena occur during aging of this adhesive.

- The first one is a reversible degradation of the adhesive (plasticization) by water ingress. From the gravimetric analysis, it is known that the useful section of the dog-bone sample is nearly saturated at $t_{1}$ and will therefore be saturated for the subsequent aging times. Then after $t_{1}$ the first phenomenon does not occur anymore.

- The second phenomenon is assumed to be a post-curing of the adhesive as it seems not $100 \%$ polymerised. It makes the mechanical properties increase. At $40^{\circ} \mathrm{C}$, after one month in sea water $\left(t_{2}\right)$, the adhesive is totally cured and the behaviour is stable. The phenomenon increases the yield stress by 10 percents $(4 \mathrm{MPa})$. Some additional analyses would be necessary to confirm the post-curing hypothesis.

- Water ingress is quite rapid in the EA9309.3NA adhesive. The adhesive is quickly saturated, but then its behaviour is very stable and finally the loss in properties is partially compensated by post-curing. Then at saturation, the loss of properties is only 10 percents ( $4 \mathrm{MPa}$ ) for the yield stress.

\section{f. Discussion on the input data}

From the previous conclusions it is obvious that the behaviour observed on the modified Arcan tests also depends on the two phenomena. For the modified Arcan tests $t_{1}, t_{2}, t_{3}$ and $t_{4}$ respectively correspond to $0.5,1,4.5$ and 10.5 months. So, according to the results obtained for the dog-bone tests, the adhesive is fully polymerised for $t_{2}, t_{3}$ and $t_{4}$ and the change in mechanical behaviour is then only due to water degradation. Results at $t_{1}$ however are due to both post-curing and water ingress. As the aim of the study is to study the effect of sea water, post-curing is an undesirable effect. Therefore, only $t_{2}, t_{3}$ and $t_{4}$ were used for the model identification. In that case the reference (unaged) state corresponds to unaged samples cured one month more at $40^{\circ} \mathrm{C}$. With this new 
reference and $t_{2}, t_{3}$ and $t_{4}$, the adhesive is fully-polymerised and only the effect of sea water has an influence. Unfortunately, this new reference was not available. Only $t_{2}, t_{3}$ and $t_{4}$ were then used for the identification. From the observation of these three aging times and the tensile tests results, some evolution hypotheses were made.

The elastic parameters $E$ and $v$ are constant during aging. Moreover, it was illustrated on bulk samples that post-curing does not affect these parameters. Then, the hypothesis was:

$$
E(c)=E^{i} \quad(10.1) \quad v(c)=v^{i}
$$

Where the exponent i refers to the initial parameters already identified.

For the yield function, $Y_{0}$, which is the elastic limit in shear, there is clearly an effect on the $90^{\circ}$ curves. Its evolution appears quicker at the beginning than at the end of aging, so the evolution was chosen to be exponential. Moreover, it shows a saturation phenomenon, as $t_{3}$ and $t_{4}$ are nearly superimposed on the $90^{\circ}$ curves. The hypothesis was made that the evolution of $Y_{0}$ was sufficient to describe the yield surface and that $\mathrm{a}_{1}$ and $\mathrm{a}_{2}$ could be taken constant:

$$
\begin{gathered}
a_{1}(c)=\beta_{1} \\
a_{2}(c)=\beta_{2} \\
Y_{0}(c)=\beta_{3} \cdot e^{-\alpha_{1} \cdot c}, \text { if } c<\gamma_{1} \\
Y_{0}(c)=\beta_{3} \cdot e^{-\alpha_{1} \cdot \gamma_{1}}, \text { if } c \geq \gamma_{1}
\end{gathered}
$$

For the hardening function, $\mathrm{q}$ and $\mathrm{b}$ describe the curvature of the curves at the beginning of the plastic part. As the curvature does not change during aging, $\mathrm{q}$ and $\mathrm{b}$ were taken constant. $\mathrm{H}$ corresponds to the slope of the experimental curves for large plastic displacements. It decreases during aging. Its evolution was chosen linear:

$$
q(c)=\beta_{4} \quad(14.1) \quad b(c)=\beta_{5} \quad \text { (14.2) } \quad H(c)=H^{i}-\alpha_{2} . c
$$

For the flow function, $\mathrm{a}_{2}{ }^{*}$ and $\mathrm{a}_{3}{ }^{*}$ were kept equal to those identified on the unaged material.

$$
a_{2}^{*}(c)=a_{2}^{* i}
$$

$$
a_{3}^{*}(c)=a_{3}^{* i}
$$

Where the exponent i refers to the initial parameters already identified.

This step is necessary to make the best hypotheses possible and to reduce the number of parameters to identify. Therefore the parameters to identify in this study were $\beta_{1}, \beta_{2}, \beta_{3}, \beta_{4}, \beta_{5}, \alpha_{1}, \alpha_{2}$ and $\gamma_{1}$.

\section{g. Identification of the effect of water degradation}

The parameters determined with the identification procedure are given in Fig. 17a. In Fig. 17b-17d are the corresponding initial yield surface, the hardening function and the initial flow function. In dotted lines are presented the results obtained in the first section (unaged state). In straight lines are the results for the moisture dependant model for several moisture concentrations. It is important to note that the straight lines correspond to an assembly that has been post-cured for one month at $40^{\circ} \mathrm{C}$. Only the effect of water degradation appears. Then the comparison of the dotted line and the straight line $\mathrm{c}=0$ allows the effect of post-curing to be revealed since the only difference between these curves is a post-curing of one month. 
The new reference identified ("Unaged+oven") is in good agreement with the experimental observations already made. Indeed, in tension $\left(0^{\circ}\right)$, post-curing increases the yield stress by about 3 $\mathrm{MPa}$. This value was already observed for bulk tensile tests. A tendency already observed in a previous study with a lower degree of cure is also present: the more polymerised the adhesive, the earlier the initial yield ellipse "drops" in negative hydrostatic stresses, while the shape for positive hydrostatic stresses is quite similar.

\begin{tabular}{|c|c|c|}
\hline & Unaged & $\begin{array}{l}\text { Unaged }+1 \text { month in the } \\
\text { oven at } 40^{\circ} \mathrm{C}\end{array}$ \\
\hline $\mathbf{E}(\mathrm{MPa})$ & 1650 & 1650 \\
\hline $\mathbf{v}$ & 0.34 & 0.34 \\
\hline$a_{1}$ & 0.64 & 0.5 \\
\hline$a_{2}$ & 0.38 & 0.6 \\
\hline $\mathbf{Y}_{0}(\mathrm{MPa})$ & 35.9 & $\begin{array}{c}41^{*} \exp \left(-0.9^{*} c\right), \text { if } c \leq 0.35 \\
41^{*} \exp \left(-0.9^{*} 0.35\right), \text { if } c>0.35\end{array}$ \\
\hline$q(M P a)$ & 9.7 & 6.8 \\
\hline b & 60 & 70 \\
\hline $\mathbf{H}(\mathrm{MPa})$ & 17 & $17^{*}\left(1-0.35^{*} c\right)$ \\
\hline$a_{2}{ }^{*}$ & 0.7 & 0.7 \\
\hline$a_{3}{ }^{*}$ & 0.05 & 0.05 \\
\hline
\end{tabular}

(a)

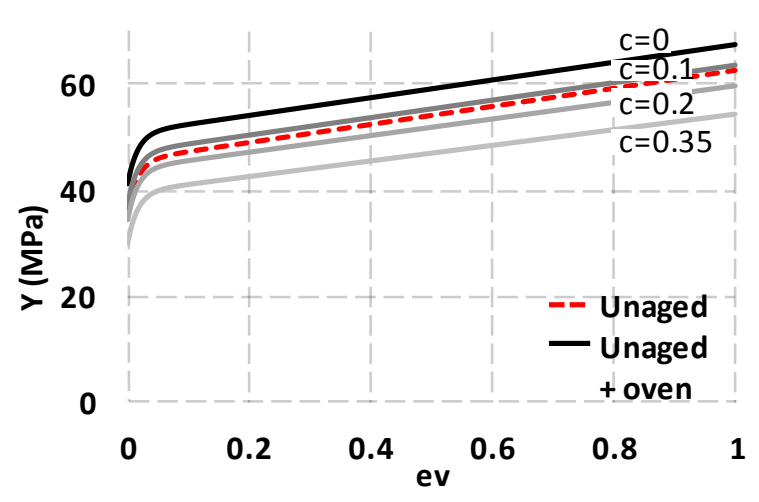

(c)

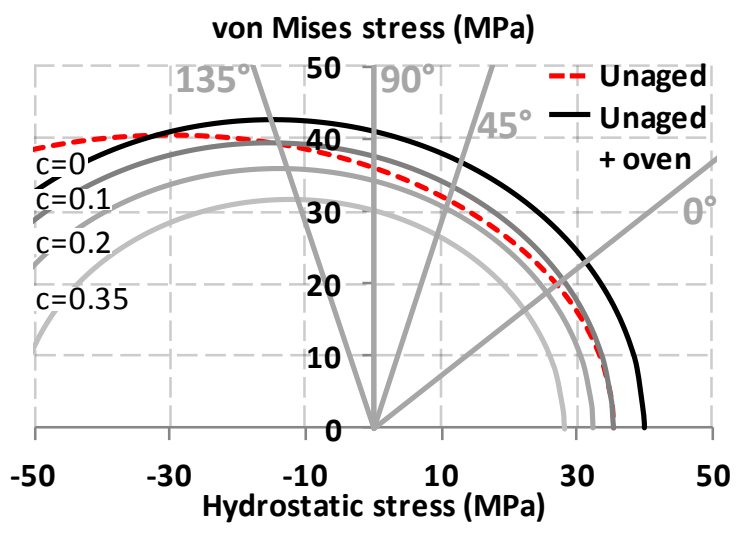

(b)

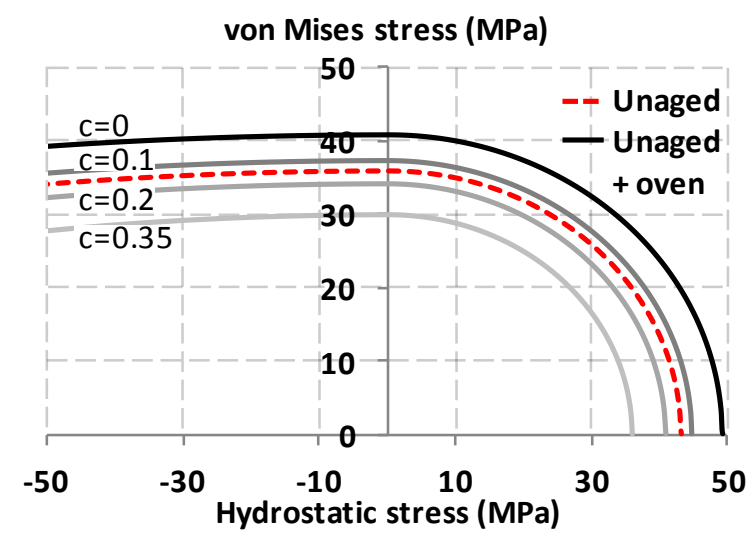

(d)

Fig. 17. Moisture dependent model identified for several moisture concentrations: (a) Parameters, (b) Initial yield surface, (c) Hardening function and (d) Initial flow surface.

In Fig. 18, the results of the moisture dependent model identification are superimposed on the Arcan experimental results from Fig. 10. The model succeeds well in describing the experimental results. Indeed, the experimental and numerical curves are nearly superimposed for $t_{2}, t_{3}$ and $t_{4}$. For the unaged state $t_{0}$, the effect of post-curing is illustrated: the numerical curves (dotted lines) correspond to the simulated response of samples post-cured one month at $40^{\circ} \mathrm{C}$ whereas the experimental curves (straight lines) are not post-cured. $t_{1}$ was removed from the curves since the experimental response is partially due to post-curing. This comparison is therefore not relevant. 


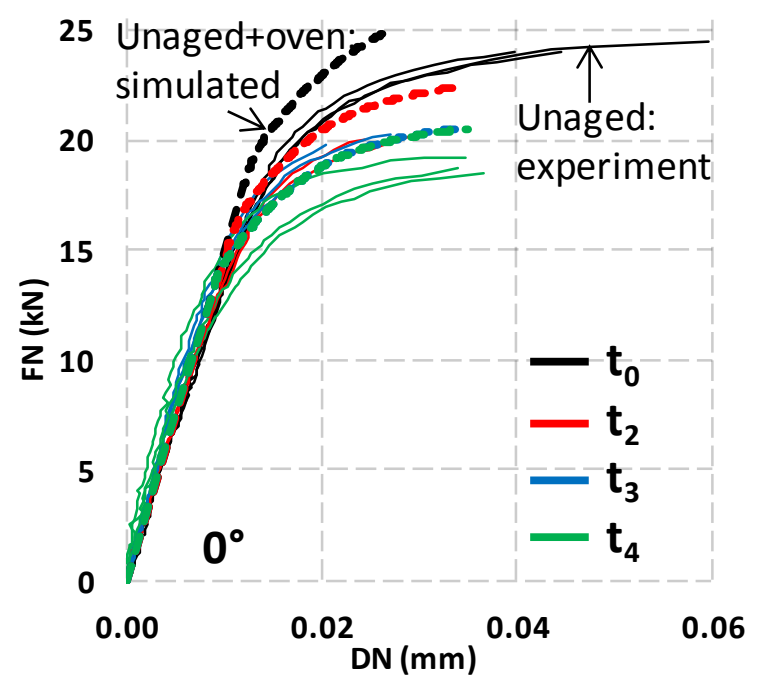

(a)

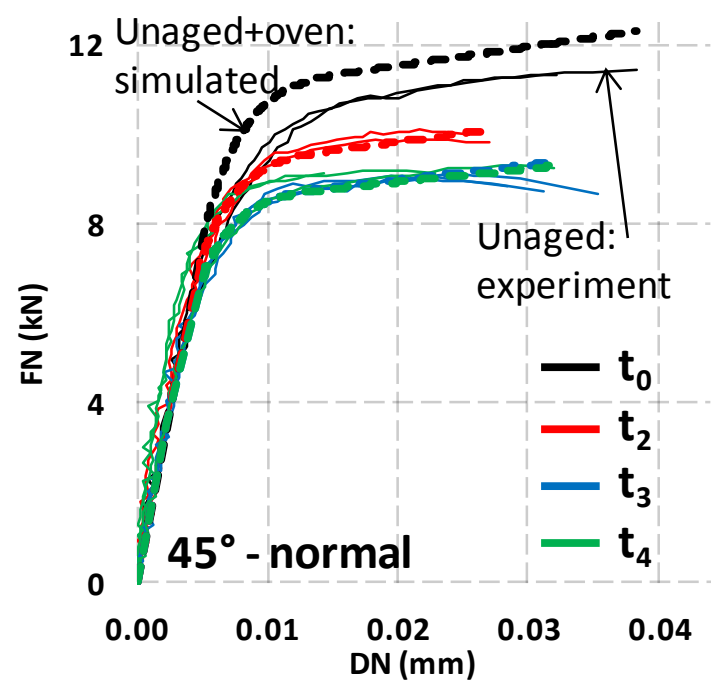

(c)

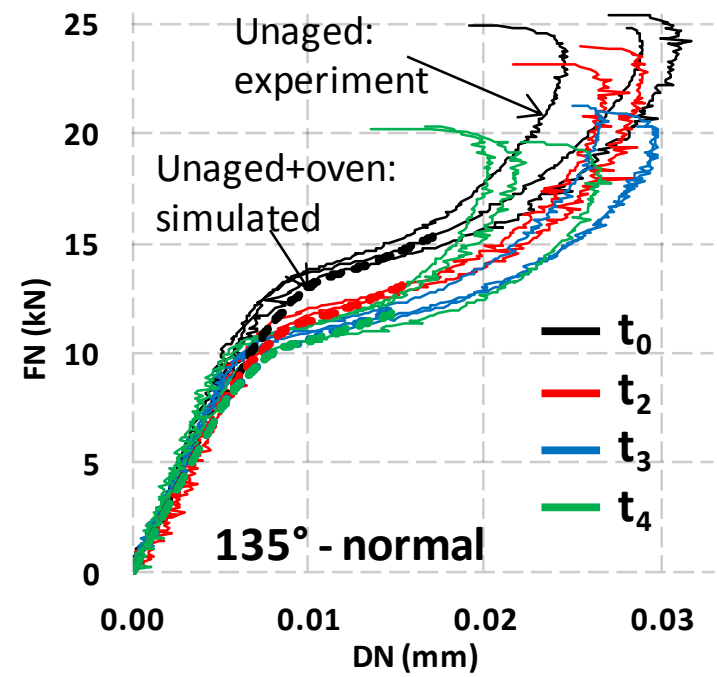

(e)

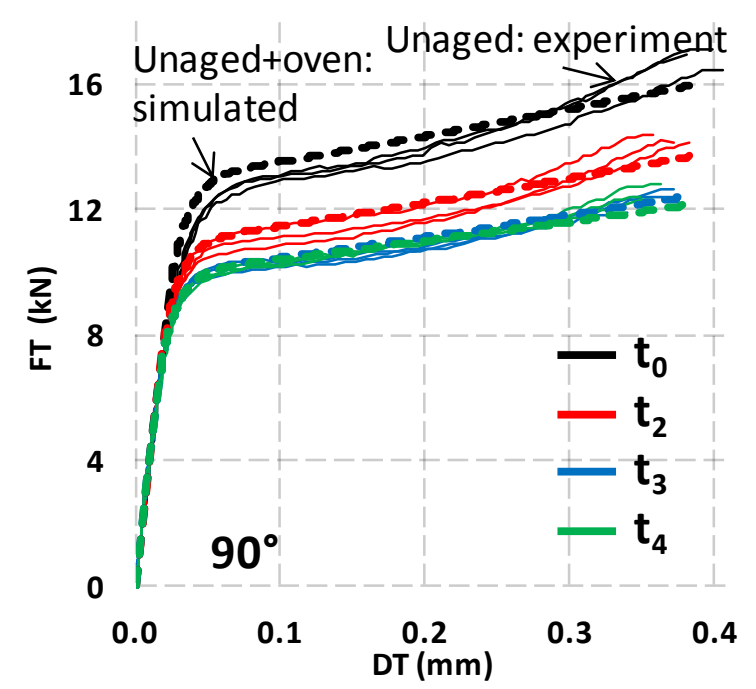

(b)

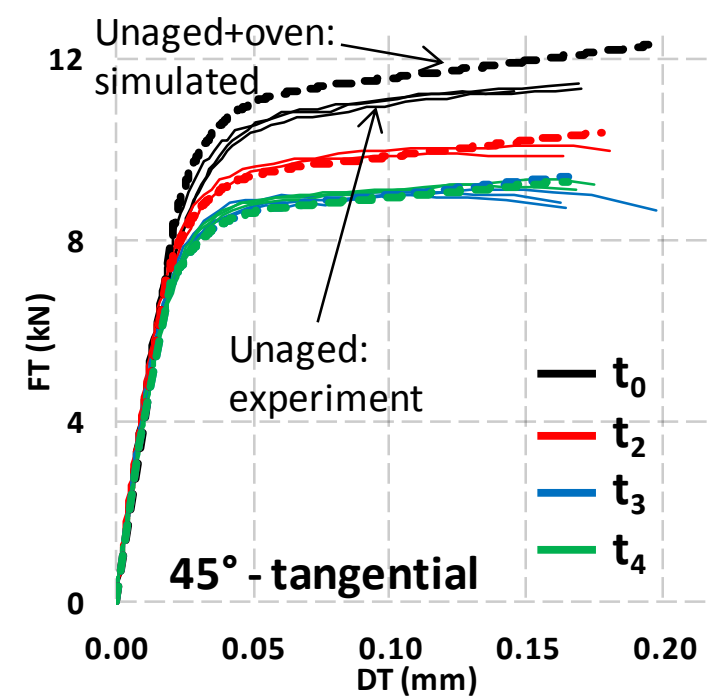

(d)

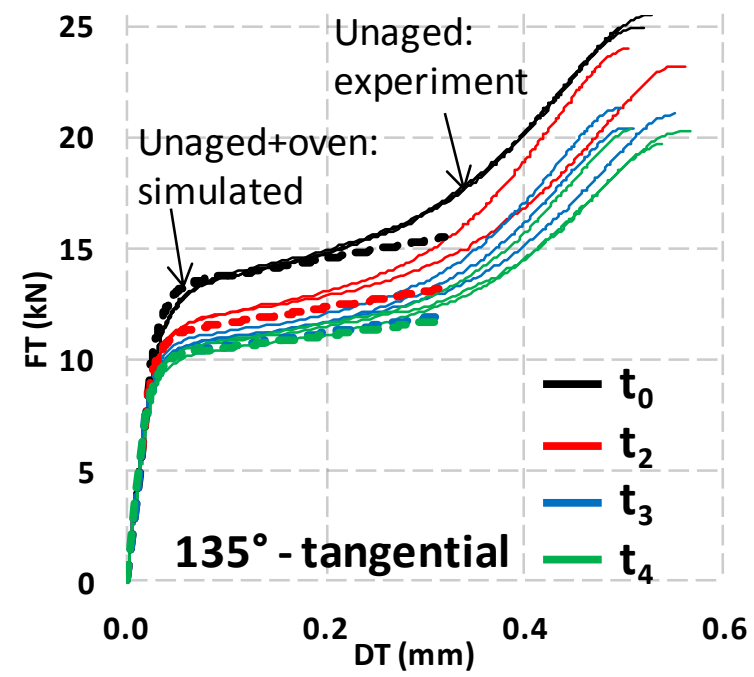

(f)

Fig. 18. Comparison of the Arcan experimental results (straight lines) and the simulated response with the moisture dependent model (dotted lines): (a) $0^{\circ}$, (b) $90^{\circ}$, (c) $45^{\circ}$-normal, (d) $45^{\circ}$-tangential, (e) $135^{\circ}$-normal, et (f) $135^{\circ}$-tangential. 


\section{Conclusions}

In this study, a constitutive model depending on the moisture concentration was proposed to describe the 3D behaviour of an adhesive in an assembly exposed to a marine environment. Modified Arcan tests were performed. They were used to determine the unaged properties through an inverse identification procedure based on the coupling of optimisation and finite-element methods. A Mahnken-Schlimmer type model was applied. Gravimetric analyses were then performed to determine the diffusion laws for the adhesive immersed in seawater. The diffusion was modelled and four aging times were identified as relevant for the study. Modified Arcan samples were then aged and tested after these four aging times.

Based on the initial Mahnken-Schlimmer parameters identified, an empirical basis for their change with the moisture concentration was established, and a global inverse identification was performed, based on the modified Arcan results. An identification procedure was developed, based on inverse techniques and several aging times. This procedure overcomes the problem of non-uniformity of the stress state in the adhesive and the mechanical property gradient due to moisture ingress.

However, a first identification attempt was unsuccessful. The phenomena occurring during aging were therefore more precisely investigated with bulk adhesive tensile tests. The main conclusion was that the degradation caused by water ingress is totally reversible and is mainly plasticization. This degradation is partially balanced by post-curing of the adhesive. As the aim of this work is to study the effect of moisture on the behaviour of the adhesive, the study should be performed on a fullypolymerised state. This was the case for the three last aging times. The global inverse identification was therefore performed again but only for these three times. The identified model describes well the behaviour at these times and it gives the unaged post-cured state. This configuration can be compared to the unaged state without post-curing. It is in agreement with the observations made during the bulk tensile tests and in previous studies, thus partially validating the model.

A complete validation is ongoing, focussing on a Tension/Compression-Torsion test developed in a previous study [37]. The tubular shape of the specimens simplifies the study as the diffusion is 1D. Moreover, the smaller specimen dimensions allow faster diffusion, thus reducing aging time. This test will simplify the study of humid aging and should allow a complete validation of the moisture dependent Mahnken-Schlimmer model. 


\section{References}

[1] Bishopp J. In: Cognard P, editor. Handbook of adhesives and sealants. Vol. 1. Oxford: Elsevier B. V.; 2005. p. 215-347.

[2] Adams RD, Comyn J, Wake WC. Structural adhesive joints in engineering. London, UK: Chapman \& Hall; 1997.

[3] da Silva LFM, Öchsner A, Adams RD. Handbook of adhesion technology. Berlin: Springer-Verlag; 2011.

[4] S. Popineau, M.E.R. Shanahan. Simple model to estimate adhesion of structural bonding during humid ageing. Int J Adhes Adhes, 26 (2006), p. 363.

[5] Y. Weitsman. Stresses in Adhesive Joints Due To Moisture and Temperature. J Compos Mater, 11 (1977), p. 378.

[6] B. Jacques, M. Werth, I. Merdas, F. Thominette, J. Verdu, Hydrolytic ageing of polyamide 11. 1. Hydrolysis kinetics in water, Polymer, 43 (2002), 6439-6447

[7] R. Leger, A. Roy, J.C. Grandidier. Non-classical water diffusion in an industrial adhesive. Int J Adhes Adhes, 30 (2010), p. 744.

[8] M.R. Bowditch. The durability of adhesive joints in the presence of water. Int J Adhes Adhes, 16 (1996), pp. 73-79.

[9] A.J. Kinloch. Durability of structural adhesives. Applied Science Publishers, Barking (1983)

[10] A.D. Crocombe, Durability modelling concepts and tools for the cohesive environmental degradation of bonded structures, International Journal of Adhesion and Adhesives, Volume 17, Issue 3, 1997, Pages 229-238.

[11] Loh WK, Crocombe AD, Abdel Wahab MM, Ashcroft IA. Environmental degradation of the interfacial fracture energy in an adhesively bonded joint. Eng Fracture Mech 2002; 69:211328.

[12] Abdel Wahab MM, Crocombe AD. Coupled stress-diffusion analysis for durability study in adhesively bonded joints. Int J Adhes Adhes 2001;22:61-73.

[13] Hua $Y$, Crocombe AB. Continuum damage modelling of environmental degradation in joints bonded with EA9321 epoxy adhesive. Int J Adhes Adhes 2008;28:302-13.

[14] J.P. Sargent. Durability studies for aerospace applications using peel and wedge tests, International Journal of Adhesion and Adhesives, Volume 25, Issue 3, June 2005, Pages 247256.

[15] A.J. Kinloch, C.F.Korenberg, K.T. Tan, J.F. Watts. Crack growth in structural adhesive joints in aqueous environments. J. Master Sci. 42, 6353-6370, 2007.

[16] R. Leger, A. Roy, J.C. Grandidier, A study of the impact of humid aging on the strength of industrial adhesive joints, International Journal of Adhesion and Adhesives, Volume 44, July 2013, Pages 66-77. 
[17] Mubashar, a., Ashcroft, I. a., Critchlow, G. W., \& Crocombe, a. D. (2009). Moisture absorptiondesorption effects in adhesive joints. International Journal of Adhesion and Adhesives, 29(8), 751-760.

[18] M. Bordes, P. Davies, J.-Y. Cognard, L. Sohier, V. Sauvant-Moynot, J. Galy, Prediction of long term strength of adhesively bonded steel/epoxy joints in sea water, International Journal of Adhesion and Adhesives, Volume 29, Issue 6, September 2009, Pages 595-608.

[19] Deb A, Malvade I, Biswas P and Schroeder J. An experimental and analytical study of the mechanical behaviour of adhesively bonded joints for variable extension rates and temperatures. Int J Adhes Adhes. 2008; 28:1-15.

[20] Dolev G, Ishai O. Mechanical Characterization of Adhesive Layer in-situ and as Bulk Material. J. Adhesion. 1981; 12:283-294.

[21] Wang $\mathrm{CH}$, Chalkley P. Plastic yielding of a film adhesive under multiaxial stresses. Int J Adhes Adhes. 2000; 20:155-164.

[22] Dean G, Crocker L, Read B, Wright L. Prediction of deformation and failure of rubbertoughened adhesive joints. Int J Adhes Adhes. 2004; 24: 295-306.

[23] Cognard JY, Créac'hcadec R, Maurice J, Davies P, Peleau M, da Silva LFM. Analysis of the Influence of Hydrostatic Stress on the Behaviour of an Adhesive in a Bonded Assembly. J Adhes Sci Technol. 2010 ; 24:1977-1994.

[24] Raghava RS, Cadell R, Yeh GSY. A yield criterion for anisotropic and pressure dependent solids such as oriented polymers. J. Mater. Sci. 1973; 8:225-232.

[25] Mahnken R, Schlimmer M. Simulation of strength difference in elasto-plasticity for adhesive materials. Int. J. Numer. Meth. Eng. 2005; 63:1461-1477.

[26] Maurice J, Cognard JY, Creac'hcadec R, Davies P, Sohier L, Mahdi S. Characterization and modelling of the 3D elastic-plastic behaviour of an adhesively bonded joint under monotonic tension/compression-shear loads: influence of three cure cycles, J Adhes Sci Technol. 2013; 27:1-25.

[27] Créac'hcadec R, Cognard JY. 2-D Modeling of the Behavior of an Adhesive in an Assembly Using a Non-Associated Elasto-Visco-Plastic Model. J. Adhesion. 2009; 85:239-260.

[28] Jousset P, Rachik M. Pressure-Dependent Plasticity for Structural Adhesive Constitutive Modeling. J Adhes Sci Technol. 2010; 24:1995-2010.

[29] Cognard JY, Davies P, Gineste B, Sohier L. Development of an improved adhesive test method for composite assembly design. Comp Sci Technol. 2005; 65:359-368.

[30] French standard NF T 76-142, Adhésifs structuraux: Méthode de préparation de plaques d'adhésifs structuraux pour la réalisation d'éprouvettes d'essai de caractérisation. 1988.

[31] French standard NF EN ISO 527, Plastiques, Détermination des propriétés en traction. 2012.

[32] GOM France SAS, www.gom.com, Ris Orangis, France. 
[33] J. Maurice. Characterization and modeling of the 3D elastic-plastic behavior of structural adhesive films for aeronautical applications. Ph.D thesis, Université de Bretagne Occidentale, 2012.

[34] N. Arnaud, R. Créac'hcadec, J.Y. Cognard. Identification of the elastic-plastic behaviour of adhesively bonded structures under multi-axial loadings: comparison of a modified Arcan test and a Tension/Compression-Torsion test. Journal of Adhesion. 2014, 91: 604-620.

[35] LMS Samtech BOSS Quattro, www.plm.automation.siemens.com, Vélizy Villacoublay, France.

[36] J. Crank, The Mathematics of Diffusion, edited by Oxford University Press, Oxford, 2nd ed. (1975).

[37] N. Arnaud, R. Créac'hcadec, J.Y. Cognard. A tension/compression-torsion test suited to analyze the mechanical behaviour of adhesives under non-proportional loadings. International Journal of Adhesion and Adhesives. 2014, 53: 3-14. 
Fig. 1. Tensile tests on bulk samples: (a) Dog-bone samples, (b) Air bubbles in the section, (c) Test and Digital Image Correlation system and (d) Stress-Strain curves.

Fig. 2. Modified Arcan test: (a) Unique sample geometry with beaks, (b) Normal and tangential directions, (c) Testing device [29] and (d) Post-processing step to retrieve the normal and tangential displacements.

Fig. 3. Modified Arcan test results for: (a) Tension $\left(0^{\circ}\right)$, normal part of tension-shear $\left(45^{\circ}\right)$, normal part of compression-shear $\left(135^{\circ}\right)$ and (b) Shear $\left(90^{\circ}\right)$, tangential part of tension-shear $\left(45^{\circ}\right)$, tangential part of compression-shear $\left(135^{\circ}\right)$.

Fig. 4. 3D-modeling of the modified Arcan test suited to an inverse identification: (a) Front view, (b) Side view and (c) Zoom close to the beaks.

Fig. 5. Results from the identification of the Mahnken-Schlimmer type model via the modified Arcan test, for several degrees of hardening $\left(e_{v}=0,0.025,0.4,1\right)$ : (a) Parameters, (b) Yield surface, (c) Hardening function and (d) Flow surface.

Fig. 6. Comparison of the model identified (dotted lines) and the experimental results (straight lines): (a) Tension $\left(0^{\circ}\right)$, normal part of tension-shear $\left(45^{\circ}\right)$, normal part of compression-shear $\left(135^{\circ}\right)$ and (b) Shear $\left(90^{\circ}\right)$, tangential part of tension-shear $\left(45^{\circ}\right)$, tangential part of compression-shear $\left(135^{\circ}\right)$.

Fig. 7. Gravimetric analysis: (a) Bulk sample geometry, (b) Mass uptake in sea water for 25 and $40^{\circ} \mathrm{C}$ immersion, for 0.4 and $1 \mathrm{~mm}$ thicknesses and (c) Zoom of the Mass uptake for short times.

Fig. 8. Simulation of water diffusion in a modified Arcan sample: (a) Finite-element model, (b) Normalized water uptake and (c) Normalized water uptake profiles for the aging times selected.

Fig. 9. Modified Arcan samples: (a) Curing in the oven and (b) Aging in sea water tanks at Ifremer.

Fig. 10. Modified Arcan test results for four aging times: (a) $0^{\circ}$, (b) $90^{\circ}$, (c) $45^{\circ}$-normal, (d) $45^{\circ}$ tangential, (e) $135^{\circ}$-normal, et (f) $135^{\circ}$-tangential.

Fig. 11. Failure profiles of the modified Arcan test during sea water aging.

Fig. 12. Force, DN and DT at failure for $t_{0}$ to $t_{4}$ for each loading direction: Mean value and standard deviation.

Fig. 13. Global inverse identification procedure.

Fig. 14. Bulk tensile specimens: (a) Samples manufactured, (b) In a sea water aging tank at Ifremer and (c) Transportation in a sealed plasticbag containing seawater.

Fig. 15. Results of tensile tests on aged bulk samples: (a) At $25^{\circ} \mathrm{C}$, (b) At $40^{\circ} \mathrm{C}$, (c) Aging times considered and (d) Superimposition of (a) and (b) and zoom on the plastic curvature.

Fig. 16. Second study with bulk tensile tests: 3 unaged samples that have spent 1 month more in the oven at $40^{\circ} \mathrm{C}$ ("Unaged+oven"), 3 samples aged 1 month in sea water at $40^{\circ} \mathrm{C}$ and dried 1 month at $40^{\circ} \mathrm{C}$ ("Water+oven"), Unaged samples ( $\mathrm{t}_{0}$ in Fig. $\left.15(\mathrm{~b})\right)$ and 1 month in sea water at $40^{\circ} \mathrm{C}\left(\mathrm{t}_{2}\right.$ in Fig. $15(b))$. 
Fig. 17. Moisture dependent model identified for several moisture concentrations: (a) Parameters, (b) Initial yield surface, (c) Hardening function and (d) Initial flow surface.

Fig. 18. Comparison of the Arcan experimental results (straight lines) and the simulated response with the moisture dependent model (dotted lines): (a) $0^{\circ}$, (b) $90^{\circ}$, (c) $45^{\circ}$-normal, (d) $45^{\circ}$-tangential, (e) $135^{\circ}$-normal, et (f) $135^{\circ}$-tangential. 
Tab

Tab. 1. Separation of the force (F) into tangential part (FT) and normal part (FN) according to the $\gamma$ angle. 